\title{
Identification of Technology Shocks in Structural VARs
}

\author{
Patrick Fève* \\ University of Toulouse (GREMAQ and IDEI) \\ and Banque de France (Research Division) \\ Alain Guay \\ UQAM, CIRPÉE and CIREQ
}

February, 2006

\begin{abstract}
The usefulness of SVARs for developing empirically plausible models is actually subject to many controversies in quantitative macroeconomics. In this paper, we propose a simple alternative two step SVARs based procedure which consistently identifies and estimates the effect of structural shocks on aggregate variables. We use the identification of the response of hours to technology improvement as an illustration. Simulation experiments from a standard business cycle model show that our approach outperforms standard SVARs. In contrast to results with standard SVARs, the effect of the technology shocks on hours is invariant to the specification of hours worked (level or difference). The two step procedure, when applied to actual data, predicts a short-run decrease of hours after a technology improvement followed by a delayed and hump-shaped positive response.
\end{abstract}

Keywords: SVARs, long-run restriction, technology shocks, consumption to output ratio, hours worked

JEL Class.: C32, E32

${ }^{*}$ Address: GREMAQ-Université de Toulouse I, manufacture des Tabacs, bât. F, 21 allée de Brienne, 31000 Toulouse. email: patrick.feve@univ-tlse1.fr. We would like to thank J. Campbell, F. Collard, M. Dupaigne, A. Kurman, J. Matheron, F. Pelgrin, L. Phaneuf, F. Portier, H. Uhlig and E. Wasmer for helpful discussions. A first version of this paper was written when the second author was visiting the University of Toulouse. This paper has benefited from helpful remarks during presentations at CIRANO Workshop on Structural VARs (november, 2004), UQAM seminar (may, 2005) and Macroeconomic Workshop (Aix/Marseille, december 2005). The traditional disclaimer applies. The views expressed herein are those of the authors and not necessary those of the Banque de France. 


\section{Introduction}

Structural Vector Autoregressions (SVARs) have been widely used as a guide to evaluate and develop dynamic general equilibrium models. Given a minimal set of identifying restrictions, SVARs represent a helpful tool to discriminate between competing theories of the business cycle. For example, Galí (1999) uses long-run restrictions à la Blanchard and Quah (1989) in a SVAR of labor productivity and hours and shows that the response of hours to a technology shock is persistently and significantly negative. This negative response of hours obtained from SVARs is then implicitly employed to favor a class of business cycle models and/or reject others (see Galí and Rabanal, 2004 and Francis and Ramey, 2004a).

The usefulness of SVARs for building empirically plausible models has been subject to many controversies in quantitative macroeconomics (see Cooley and Leroy, 1985, Bernanke, 1986 and Cooley and Dwyer, 1998). More recently, the debate about the effect of technology improvements on hours worked has triggered the emergence of several contributions concerned with the ability of SVARs to adequately measure the impact of technology shocks on aggregate variables.

Using Dynamic Stochastic General Equilibrium (DSGE) models estimated on US data as their Data Generating Process (DGP), Erceg, Guerrieri and Gust (2004) show that the effect of a technology shock on hours worked is not precisely estimated with SVARs. They suggest that part of their results originate from the difficulty to disentangle technology shocks from other shocks that have highly persistent, if not permanent, and important effects on labor productivity. ${ }^{1}$ For example, they show that when the persistence of the non-technology shock decrease - and thus the persistence of hours -, for a given standard error of this shock, the estimated response of hours is less biased. Their results indicate that SVARs with long-run restriction deliver more reliable results when the non-technology component in SVARs displays lower persistence. Their findings also suggest to include in SVARs other variables with lower serial correlation.

Chari, Kehoe and McGrattan (2005) simulate a prototypical business cycle model estimated by Maximum Likelihood on US data with structural shocks as well as measurement errors. They show that the SVAR with a specification of hours in difference (DSVAR) leads to a negative response of hours under a business cycle model in which hours respond positively. Moreover, they show that a level specification of hours (LSVAR) does not uncover the true response of hours and implies a large upward bias. Their findings echo some empirical evidences since LSVAR and DSVAR models deliver conflicting responses of hours. A significant part of their

\footnotetext{
${ }^{1}$ By highly persistent and important effect, we mean that the transitory component of the variable is highly persistent and explains a substantial fraction of its variance.
} 
results originates from the inability of SVARs with a finite number of lags to properly capture the true dynamic structure of the model. According to them, the auxiliary assumption of the VAR that the stochastic processes for labor productivity and hours are well approximated by an VAR with a finite number of lags does not hold. They show that this problem can be eliminated if a relevant state variable is introduced in the SVAR. Unfortunately, the lack of observability of such a variable (for example, capital stock and shocks) makes its use impossible. However, even if such a meaningful variable is virtually unobserved, we can always think about observable relevant instrumental variables that share approximatively the same dynamic structure.

Christiano, Eichenbaum and Vigfusson (2005) argue that SVARs are still a useful guide for developing models. They find that most of the deceiving results with SVARs in Chari, Kehoe and McGrattan (2005) come from the values assigned to the standard errors of shocks in their economy. They notably show that when the model is more properly estimated, the standard error of the non-technology shocks is twice lower than the standard error of the technology shock. In such a case, the bias in SVARs with labor productivity and hours is strongly reduced. Their findings show that the behavior of hours is closely related to the non-technology shock and the reliability of SVARs is thus highly sensitive to the volatility of this shock. Evidence from their simulation experiments implicitly suggests using other variables which are less sensitive to the volatility of non-technology shocks and/or which contains a sizeable part of technology shocks.

In light of the above quantitative findings, we propose a simple alternative method to consistently estimate technology shocks and their short-run effects on aggregate variables. As an illustration and a contribution to the current debate, we essentially concentrate our analysis on the response of hours worked. However, our empirical strategy can be easily implemented to other variables of interest. Although imperfect, we maintain the labor productivity variable as a way to identify technology shocks using long-run restrictions. We argue that SVARs can deliver accurate results if more efforts are made concerning the choice of the stationary variables. More precisely, hours must be excluded from SVARs and replaced by any variable which presents better stochastic properties. The introduction of a highly persistent variable as hours worked in the SVARs confounds the identification of the permanent and transitory shocks and thus contaminates the corresponding impulse response functions. Following the previous quoted contributions which use simulation experiments, the selected variable must satisfy the following stochastic properties. First, the variable must display less controversies about its stationarity. ${ }^{2}$

\footnotetext{
${ }^{2}$ Pesavento and Rossi (2005) and Francis, Owyang and Roush (2005) propose other methods to deal with the presence of highly persistent process.
} 
Second, the variable must behave more as a capital variable than hours worked do, so that finite VAR can more easily approximate the true underlying dynamics of the data. Third, the variable must contain a sizeable technology component and present less sensitivity to highly persistent non-technology shocks. We argue that the consumption to output ratio (in logs) is an interesting candidate to fulfil these three requirements. The ratio is stationary and consequently displays less persistence than hours worked. Moreover, the consumption to output ratio represents probably a better approximation of the state variables than hours worked and appears less sensitive to transitory shocks. The first requirement can be directly found with actual data, since standard unit root tests reject the null hypothesis of an unit root. The two other requirements can be quantitatively (through numerical experiments) and analytically deduced from equilibrium conditions of dynamic general equilibrium models which satisfactory fit the data. In addition, Cochrane (1994) has already shown in SVARs that the consumption to output ratio allows to suitably characterize permanent and transitory components in GNP.

The proposed approach consists in the following two steps. In a first step, a SVAR model which includes labor productivity growth and consumption to output ratio is considered to consistently estimate technology shocks using with a long-run restriction. In the second step, the impulse response functions of hours (or any other aggregate variable under interest) at different horizons are obtained by a simple OLS regression of hours on the estimated technology shock for different lags. We show that the impulse response functions are consistently estimated whether hours worked are projected in level or in difference in the second step. Consequently, our approach does not suffer from the specification choice of hours as in the standard SVAR approach. Our method can be viewed as a combination of a SVAR approach in the line of Blanchard and Quah (1989), Galí (1999) and Christiano, Eichenbaum and Vigfusson (2004) and the regression equation used by Basu, Fernald and Kimball (2004) in their growth accounting exercise.

To evaluate this proposed two step approach, we perform simulation experiments using a standard business cycle model with a permanent technology shock and stationary preference and government consumption shocks. This models includes three wedges that mainly explain US aggregate fluctuations for post war period (Chari, Kehoe and McGrattan, 2004). The results show that our approach, denoted CYSVAR, performs better than the DSVAR and LSVAR models. In particular, the bias of the estimated impulse response functions is strongly reduced. In contrast with the results for the DSVAR and LSVAR models, we also show that the specification of hours (in level or in difference) does not matter. Moreover, the estimated technology shock using CYSVAR is strongly correlated with the true technology shock while weakly with 
the non-technology shock. In other words, the estimated technology shock is not contaminated by other shocks that drive up or down hours worked. Consequently, the estimated response of hours obtained in the second step displays small bias. Conversely, existing approaches (DSVAR and LSVAR) perform poorly. In particular, their estimates of the technology shock are contaminated by the non-technology shock. We also find in the three shock version of the model that the CYSVAR approach which includes two variables outperforms SVARs with three variables (productivity growth, hours and consumption to output ratio). Although the three variable SVARs contain at least the same information (output, hours worked and consumption), this result comes from the fact that finite autoregressions cannot properly approximate the time series behavior of hours. Consequently, hours contaminate the estimation of the technology shock in the three variable SVAR. This supports the use a parsimonious SVARs in the first step to consistently estimate technology shocks.

An application with US data for the period 1955Q1-2002Q4 shows that hours significantlty decrease on impact after a positive technology shock and increase after some periods. These results are robust to the specification of hours. The shape of the response of hours is very similar to Basu, Fernald and Kimball (2004), Francis and Ramey (2004b), Uhlig (2004), Vigfusson (2004) and Pesavento and Rossi (2005) who show that the negative (or almost zero) response of hours on impact is followed by a subsequent positive response. We also investigate the sensitivity of our results to the presence of breaks in labor productivity growth (Fernald, 2004). The impulse response functions are qualitatively left unaffected.

The paper is organized as follows. In a first section, we briefly review some empirical results about the effect of a technology shock on hours worked. In section 2, we present our two step approach. The third section is devoted to the exposition of the business cycle model. Section 4 discusses in details our simulation experiments. In section 5, we present the empirical results. The last section concludes.

\section{SVARs and the Hours Worked Debate}

In this section, we review some evidence about the effect of a technology shock on hours worked. The empirical analysis uses quarterly U.S. data for the period 1955Q1-2002Q4. We use data on logged real gross per capita product in chained 2000 dollars $\left(y_{t}\right)$ and logged total hours worked per capita $\left(h_{t}\right)$. These series relate to the non farm business sector. As is conventional in the literature, productivity is defined as the average labor productivity ( $y_{t}-h_{t}$, in $\operatorname{logs}$ ). We also consider the consumption to output ratio $\left(c_{t}-y_{t}\right.$, in logs). This ratio is obtained by 
divided the nominal expenditures of non-durables and services by the nominal Gross Domestic Product. ${ }^{3}$ Data on these three variables are reported in Figure 1. This figure shows that hours displays a persistent downward trend from 1955 to 1980, whereas a persistent increase during the subsequent period. Conversely, the consumption to output ratio does not display similar patterns.

In order to assess the dynamic properties of hours and consumption to output ratio, we first perform unit root tests. We begin by testing the null hypothesis of a unit root in these two variables using the Augmented Dickey Fuller (ADF) test. For each variable, we regress the growth rate on a constant, lagged level and four lags of the first difference. The ADF test statistic is equal to -2.50 for hours and -3.18 for the consumption to output ratio. This hypothesis cannot be rejected at the 10 percent level for hours, whereas it is rejected at the 5 percent level for the consumption to output ratio. ${ }^{4}$ Our results on hours are thus in the line with those obtained by Galí (1999), Galí and Rabanal (2004) and Christiano, Eichenbaum and Vigfusson (2004). According to the $\mathrm{ADF}$ test, we can conclude that the consumption to output ratio is stationary but not hours worked. It is however well known that the ADF test has very low power when the alternative is a persistent stationary process. Therefore, we now test the null hypothesis that hours worked series is stationary using the KPSS test. ${ }^{5}$ This test is implemented using eight lags in the Newey and West estimator of the long-run covariance matrix. We cannot reject the null hypothesis of stationarity at the 1 percent level, as the KPSS test statistic is $0.69 .{ }^{6}$ However, the null hypothesis of stationarity is rejected at the 5 percent significant levels. These two unit root tests then favor the hypothesis of the unit root for hours worked.

We now estimate Structural Vector Autoregressive (SVAR) models for four alternative specifications. In each of these specifications, we identify technology shocks as the only shocks that can affect the long-run level of labor productivity. We first consider a bivariate LSVAR specification which includes labor productivity growth and hours in level (Christiano, Eichenbaum and Vigfusson, 2004). We then consider a bivariate DSVAR specification in which hours are now taken in first difference. As pointed out by Galí (1999) (2004a) and (2004b), Galí and Ra-

\footnotetext{
${ }^{3}$ The data used in our estimation are extracted from the FRED II and the BEA databases. Our dataset is that of Galí and Rabanal (2004) and corresponds to one of the alternative measures in Christiano, Eichenbaum and Vigfusson (2004). So as to define our macroeconomic variables, we use the following time series: i) gross domestic output of the non farm business sector $(L X N F O)$; ii) total hours in the non farm business sector $(L X N F H)$; iii) total non institutional civilian population over $16(L N N)$; iv) personal consumption expenditures: services (PCESV); v) personal consumption expenditures: nondurable goods (PCND) and vi) gross domestic product (GDP).

${ }^{4}$ The critical values of the ADF test statistic at 1,5 and 10 percent significance levels are $-3.49,-2.88$ and -2.57 .

${ }^{5}$ See Kwiatkowski et al. (1992).

${ }^{6}$ The critical values of the KPSS test statistic at 1,5 and 10 percent significance levels are $0.74,0.46$ and 0.35 .
} 
banal (2004) and Francis and Ramey (2004a) and suggested by the previous unit root tests, this specification accounts for a possible non-stationarity in hours. We move beyond the bivariate system and we now include in both the LSVAR and DSVAR specifications the consumption to output ratio. By doing so, we want to assess the sensitivity of the results to an additional variable in the SVAR (see Galí, 1999, Francis and Ramey, 2004a, and Christiano, Eichenbaum and Vigfusson, 2004). Notice that this ratio is specified in level as unit root tests suggest its stationarity. ${ }^{7}$

As is usual, we start by estimating the reduced form vector autoregression of order $p$

$$
\mathbf{X}_{t}=\mathbf{B}_{1} \mathbf{X}_{t-1}+\cdots+\mathbf{B}_{p} \mathbf{X}_{t-p}+\varepsilon_{t}, \quad \mathrm{E} \varepsilon_{t} \varepsilon_{t}^{\prime}=\boldsymbol{\Sigma}
$$

We follow Galí and Rabanal (2004) and Christiano, Eichenbaum and Vigfusson (2004) and we set $p=4$. The variable $\mathbf{X}_{t}$ includes labor productivity growth as first variable for each specification. The other variables that enter in $\mathbf{X}_{t}$ corresponds to different SVAR specifications. Let us define $\mathbf{C}(L)=\left(\mathbf{I}-\mathbf{B}_{1} L-\cdots-\mathbf{B}_{p} L^{p}\right)^{-1}$, so that

$$
\mathbf{X}_{t}=\mathbf{C}(L) \varepsilon_{t}
$$

where $\mathbf{I}$ is the identity matrix and $L$ is the lag operator, i.e. $L \mathbf{X}_{t}=\mathbf{X}_{t-1}$. The reduced form innovations $\varepsilon_{t}$ are linear combinations of the structural shocks $\boldsymbol{\eta}_{t}$, i.e. $\varepsilon_{t}=\mathbf{A}_{\mathbf{0}} \boldsymbol{\eta}_{t}$, for some non singular matrix $\mathbf{A}_{\mathbf{0}}$. As usual, we impose an orthogonality assumption on the structural shocks, which combined with a scale normalization implies $\mathbf{E} \boldsymbol{\eta}_{t} \boldsymbol{\eta}_{t}^{\prime}=\mathbf{I}_{2}$. This gives us three constraints out of the four needed to completely identify $\mathbf{A}_{\mathbf{0}}$. To setup the last identifying constraint, let us define $\mathbf{A}(L)=\mathbf{C}(L) \mathbf{A}_{\mathbf{0}}$. Given the ordering of $\mathbf{X}_{t}$, we simply require that $\mathbf{A}(1)$ be lower triangular, so that only technology shocks can affect the long-run level of productivity. This amounts to imposing that $\mathbf{A}(1)$ is the Cholesky factor of $\mathbf{C}(1) \mathbf{\Sigma} \mathbf{C}(1)^{\prime}$. Given consistent estimates of $\mathbf{C}(1)$ and $\boldsymbol{\Sigma}$, we easily obtain an estimate for $\mathbf{A}(1)$. Retrieving $\mathbf{A}_{\mathbf{0}}$ is then a simple task using the formula $\mathbf{A}_{\mathbf{0}}=\mathbf{C}(1)^{-1} \mathbf{A}(1)$.

The impulse response functions, as well as their $95 \%$ confidence intervals, ${ }^{8}$ are reported in Figures 2 and 3. Panel (a) of Figure 2 displays the responses of hours to a permanent technology shock in the LSVAR specification. The response is positive and hump-shaped, though not statistically significant. As has been previously emphasized by Chari, Kehoe and McGrattan (2005), this LSVAR specification is essentially uninformative, since a large number of competing

\footnotetext{
${ }^{7}$ Francis and Ramey (2004a) and Christiano, Eichenbaum and Vigfusson (2004) include this cointegration relationship between consumption and output in their SVARs.

${ }^{8}$ These confidence intervals are computed by standard bootstrap methods, using 1000 draws from the sample residuals.
} 
DSGE models could produce responses contained in the confidence interval. Panel (b) of Figure 2 displays the responses of hours to a permanent technology shock in the DSVAR specification. Hours fall during two periods and the response remain negative for each horizon. Notice that the response is statistically significant on impact, as well as one period after the shock. These results are consistent with the empirical evidence reported in Galí (1999) and Galí and Rabanal (2004). Panels (a) and (b) of Figure 3 report the responses of hours in a three-variables system. Most of the quantitative patterns are left unaffected by the three-variables system. In the LSVAR specification (see panel (a) of Figure 3), the response of hours is still hump-shaped but not precisely estimated. The main difference concerns the impact response which becomes slightly negative, although not significant. For the DSVAR specification, the response of hours to a positive technology shock is negative during four periods, but not significantly different from zero.

In conclusion to this section, empirical evidence reports conflicting results about the effect of a technology shock on hours worked. The level specification displays a positive hump-shaped response whereas the difference specification implies a decrease in hours. Notice that the threevariables system does not help so much as most of the conflicting results are maintained. Christiano, Eichenbaum and Vigfusson (2004) provide similar evidence using six-variables SVARs. In their LSVAR specification, the response of hours is positive, although not precisely estimated, while the response is negative in the DSVAR specification. The conflicting results mainly originate from the specification of hours. The problem remains unsolved: which specification of hours to adopt in SVARs? Since hours are highly persistent, we can not determine using unit root tests in small sample which specification to adopt. In the next section, we will propose a simple two-step approach which does not suffer from the problem resulting from the time series properties of hours worked.

\section{The Two Step Approach}

The goal of our approach is to accurately identify the technology shocks in the first step using an adequate stationary variable in the VAR model. A large part of the performance of the two step approach depends on the time series properties of this variable. This latter can be interpreted as an instrument allowing to retrieve with more precision the true technology shock. The variable choice is motivated in part by simulation results in Erceg, Guerrieri and Gust (2004), Chari Kehoe and McGrattan (2005) and Christiano, Eichenbaum and Vigfusson (2005). They show that, when hours worked are contaminated by an important persistent transitory component, the SVAR performs poorly in their experiments. In an interesting paper, Chari, Kehoe and 
McGrattan (2004) propose a method in order to account for economic fluctuations based on the measurement of various wedges. They assess what fraction of the output fluctuations can be attributed to each wedge separately and in combinations. For the postwar period, the efficiency and labor wedges are proeminent to explain output movement. Investment wedge plays a minor role in the postwar period and especially at low frequencies of output fluctuations. They also find that the government consumption component accounts for an insignificant fraction of fluctuations in output, labor, consumption and investment which is compatible with the results in Burnside and Eichenbaum (1996). The results in Chari Kehoe and McGrattan (2004) suggest that the observed fluctuations and persistence of hours worked depend on an important portion of the labor wedge. In contrast, in their prototypical economy, the consumption-output ratio is less dependent on labor wedge and is much more sensitive to the government consumption wedge. However, this wedge appears to be negligible in the dynamic of real variables such as consumption and output. As a consequence, the transitory component of the consumption-output ratio is then probably less important than the one corresponding to the permanent shock. According to this, the consumption-output ratio is a more promising variable to use in a VAR for identifying technology and non-technology and their respective impulse responses than hours worked. Cochrane (1994) also argues that the consumption to output ratio contains useful information to disentangle the permanent to the transitory component. Moreover, in data, we can reject the unit root for this ratio and the empirical autocorrelation function is clearly less persistent that the one for hours. So we decide to introduce this ratio as instrument to identify the technology shocks. With this identified shocks at the first step, we can then evaluate the impact of these shocks on a variable of interest (for example, hours) in the second step.

Step 1: Identification of technology shocks

We consider a VAR model which includes productivity growth and consumption to output ratio (in logs). We start by specifying a $\operatorname{VAR}(\mathrm{p})$ model in these two variables:

$$
\left(\begin{array}{c}
\Delta\left(y_{t}-h_{t}\right) \\
c_{t}-y_{t}
\end{array}\right)=\sum_{i=1}^{p} \boldsymbol{B}_{i}\left(\begin{array}{c}
\Delta\left(y_{t-i}-h_{t-i}\right) \\
c_{t-i}-y_{t-i}
\end{array}\right)+\varepsilon_{t}
$$

where $\varepsilon_{t}=\left(\varepsilon_{1, t}, \varepsilon_{2, t}\right)^{\prime}$ and $\mathrm{E}\left(\varepsilon_{t} \varepsilon_{t}^{\prime}\right)=\boldsymbol{\Sigma}$. Under usual conditions, this $\operatorname{VAR}(\mathrm{p})$ model admits a $\operatorname{VMA}(\infty)$ representation

$$
\left(\begin{array}{c}
\Delta\left(y_{t}-h_{t}\right) \\
c_{t}-y_{t}
\end{array}\right)=\boldsymbol{C}(L) \varepsilon_{t}
$$

where $\boldsymbol{C}(L)=\left(\boldsymbol{I}_{2}-\sum_{i=1}^{p} \boldsymbol{B}_{i} L^{i}\right)^{-1}$. The SVAR model is represented by the following $\operatorname{VMA}(\infty)$ representation

$$
\left(\begin{array}{c}
\Delta\left(y_{t}-h_{t}\right) \\
c_{t}-y_{t}
\end{array}\right)=\boldsymbol{A}(L)\left(\begin{array}{c}
\boldsymbol{\eta}_{t}^{T} \\
\boldsymbol{\eta}_{t}^{N T}
\end{array}\right)
$$


where $\boldsymbol{\eta}_{t}^{T}$ is period $t$ technology shock, whereas $\boldsymbol{\eta}_{t}^{N T}$ is period $t$ non-technology shocks. By normalization, these two orthogonal shocks have zero mean and unit variance. The identifying restriction implies that the non-technology shock has no long-run effect on labor productivity. This means that the upper triangular element of $\boldsymbol{A}(L)$ in the long run must be zero, i.e. $\boldsymbol{A}_{12}(1)=$ 0 . In order to uncover this restriction from the estimated $\operatorname{VAR}(\mathrm{p})$ model, the matrix $\boldsymbol{A}(1)$ is obtained as the Choleski decomposition of $\boldsymbol{C}^{-1}(1) \boldsymbol{\Sigma} \boldsymbol{C}^{-1}(1)^{\prime}$. The structural shocks are then directly deduced up to a sign restriction:

$$
\left(\begin{array}{c}
\boldsymbol{\eta}_{t}^{T} \\
\boldsymbol{\eta}_{t}^{N T}
\end{array}\right)=(C(1) A(1))^{-1}\left(\begin{array}{l}
\varepsilon_{1, t} \\
\varepsilon_{2, t}
\end{array}\right)
$$

We argue that replacing hours by the consumption to output ratio can help to identify more accurately the true technology shocks. In contrast to hours worked, the consumption to output ratio is probably less contaminated by important persistent transitory shocks. Its use in the SVAR model can reduce the confusion of the the true permanent technology shocks with the transitory shocks.

Step 2: Estimation of the responses of hours to a technology shock Suppose the following infinite moving average representation for hours worked as a linear function of a technological and a non-technological shocks:

$$
h_{t}=\boldsymbol{a}_{21}(L) \boldsymbol{\eta}_{t}^{T}+\boldsymbol{a}_{22}(L) \boldsymbol{\eta}_{t}^{N T}
$$

where the individual $a_{21, k}$ measures the impact of the technology shock at lag $k$. The identifying restriction of Step 1 implies that non-technology shocks are orthogonal to technology shocks by construction, i.e. $\mathrm{E}\left(\boldsymbol{\eta}_{t-i}^{T}, \boldsymbol{\eta}_{t-j}^{N T}\right)=0 \quad \forall i, j$ and that the technology and non-technology shocks are serially uncorrelated which implies $\mathrm{E}\left(\boldsymbol{\eta}_{t}^{T}, \boldsymbol{\eta}_{t-i}^{T}\right)=0$ and $\mathrm{E}\left(\boldsymbol{\eta}_{t}^{T}, \boldsymbol{\eta}_{t-i}^{T}\right)=0 \quad \forall i \neq 0$,

Let $\hat{\boldsymbol{\eta}}_{t}^{T}$ denotes the estimated technology shock obtained from the SVAR model in the first step. According to the debate on the right specification of hours worked, we examine three specifications to measure the impact of technology on this variable. In the first specification, hours series is projected in level on the identified technology shocks while in the second specification, hours series is projected in difference. Finally, in the third specification, the hours series is projected on its own first lag and the identified technology shocks. This latter specification is more flexible in the sense that we do not impose a unit root but we allow to the $\operatorname{AR}(1)$ parameter to be freely estimated. The first and the second specifications are in fact a restricted version of the third with an $\operatorname{AR}(1)$ parameter restricted to be zero or one. 
Let us now present in more details the three specifications. In the first one, we regress the logs of hours worked on the current and past values of the identified technology shocks $\hat{\boldsymbol{\eta}}_{t}^{T}$ in the first-step:

$$
h_{t}=\sum_{i=0}^{q} \boldsymbol{\theta}_{i} \hat{\boldsymbol{\eta}}_{t-i}^{T}+\boldsymbol{\nu}_{t}
$$

where $q<+\infty$. $\boldsymbol{\nu}_{t}$ is a composite error term that accounts for non-technology shocks and the remainder technology shocks.

A standard OLS regression provides the estimates of the population responses of hours to the present and lagged values of the technology shocks, namely:

$$
\hat{a}_{21, k}=\widehat{\boldsymbol{\theta}}_{k} .
$$

Hereafter, we refer to this approach as CYSVAR- $h$. According to the debate on the appropriate specification of hours, this variable is regressed in first difference on the current and past values of the identified technology shocks. Hereafter, we refer to this approach as CYSVAR- $\Delta h$. The response of hours worked to a technology shock is now estimated from the regression:

$$
\Delta h_{t}=\sum_{i=0}^{q} \tilde{\boldsymbol{\theta}}_{i} \hat{\boldsymbol{\eta}}_{t-i}^{T}+\tilde{\boldsymbol{\nu}}_{t} .
$$

As hours are specified in first difference, the estimated response at horizon $k$ is obtained from the cumulated OLS estimates:

$$
\hat{a}_{21, k}=\sum_{i=0}^{k} \widehat{\tilde{\boldsymbol{\theta}}}_{i}
$$

Finally, an interesting avenue is to adopt a more flexible approach by freely estimating the autoregressive parameter of order one for hours. This lets the data discriminate between the presence of an unit root in the stochastic process of hours worked. Hereafter, we refer to this approach as CYSVAR- $A R(1)$. The response to a technology shock is now estimated from the regression of hours on one lag of itself and lags of the technology shock:

$$
h_{t}=\boldsymbol{\rho} h_{t-1}+\sum_{i=0}^{q} \tilde{\tilde{\boldsymbol{\theta}}}_{i} \hat{\boldsymbol{\eta}}_{t-i}^{T}+\tilde{\tilde{\boldsymbol{\nu}}}_{t} .
$$

The estimated response at horizon $k$ is obtained from the OLS estimates of $\boldsymbol{\rho}$ and $\boldsymbol{\theta}_{i}(i=1, \ldots, q)$ :

$$
\hat{a}_{21, k}=\sum_{i=0}^{k} \hat{\boldsymbol{\rho}}^{i} \stackrel{\tilde{\tilde{\boldsymbol{\theta}}}}{k-i} .
$$

In the following proposition, we show that the OLS estimators of the effect of technology shocks are consistent estimators of the true ones for the three specifications. 
Proposition 1 Assume the infinite moving average representation (3) for hours worked and consider the estimation of the finite VAR in the first step as defined in (2) and the three projections (4), (5) and (6) in the second step. The OLS estimators $\hat{a}_{21, k}$ converge in probability to $a_{21, k}$ for the three specifications, $\forall k$.

The proof is given in Appendix A.

In Proposition 1, the property of consistency is derived under the assumption that hours worked follow a stationary process. While the specification of hours in difference could provide a good statistical approximation of this variable in small sample, hours worked per capita are bounded and therefore the stochastic process of this variable cannot have a unit root asymptotically. By definition, the consistency property of an estimator is an asymptotically concept so only the asymptotic behavior of hours worked is of interest. Consequently, the consistency of the OLS estimators for the three specifications is derived only under the assumption that hours worked per person is a stationary process. It is worth noting that the specification of hours (level or first difference) does not asymptotically matter. However, the small sample behavior of the three specifications can differ.

Confidence intervals of impulse response functions are computed using a consistent estimator of the asymptotic variance-covariance of the second step parameters. Newey (1984) shows how to derive such a consistent estimator of the asymptotic variance-covariance matrix. In particular, he shows how a two step procedure such as ours can be represented as member of method of moments estimators. With this representation in hand, he derives the asymptotic variancecovariance matrix of the second step estimator. This asymptotic variance-covariance matrix takes into account the generated regressors problem occurring in the first step and allows for unknown serial dependence of the residuals in the second step. In Appendix B, we provide more details on the implementation and computation of the consistent estimator proposed by Newey (1984) for the asymptotic variance-covariance matrix of our two step estimator.

\section{A Business Cycle Model}

We consider a standard business cycle model that includes three shocks. The utility function of the representative household is given by

$$
E_{t} \sum_{i=0}^{\infty} \beta^{i}\left(\log \left(C_{t+i}\right)+\psi \chi_{t+i} \log \left(1-H_{t+i}\right)\right)
$$

where $\beta \in(0,1)$ denotes the discount factor and $\psi>0$ is a time allocation parameter. $E_{t}$ is the expectation operator conditional on the information set available at time $t . C_{t}$ and $H_{t}$ represent 
consumption and labor supply at time $t$. The labor supply $H_{t}$ is subjected to a preference shock $\chi_{t}$, that follows a stationary stochastic process.

$$
\log \left(\chi_{t}\right)=\rho_{\chi} \log \left(\chi_{t-1}\right)+\left(1-\rho_{\chi}\right) \log \bar{\chi}+\sigma_{\chi} \varepsilon_{\chi, t}
$$

where $\bar{\chi}>0,\left|\rho_{\chi}\right|<1, \sigma_{\chi}>0$ and $\varepsilon_{\chi, t}$ is iid with zero mean and unit variance. As noted by Galí (2005), this shock can be an important source of fluctuations as it accounts for persistent shifts in the marginal rate of substitution between goods and work (see Hall, 1997). Such shifts capture persistent fluctuations in labor supply following changes in labor market participation and/or changes in the demographic structure. Additionally, this preference shock allows us to simply account for other distortions on the labor market, labelled labor wedge in Chari, Kehoe and McGrattan (2004). For example, they show that a sticky-wage economy or a real economy with unions will map it into a simple model economy with this type of shock. Note that this shock is observationally equivalent to a tax shock on labor income.

The representative firm use capital $K_{t}$ and labor $H_{t}$ to produce a final good $Y_{t}$. The technology is represented by the following constant returns-to-scale Cobb-Douglas production function

$$
Y_{t}=K_{t}^{\alpha}\left(Z_{t} H_{t}\right)^{1-\alpha}
$$

where $\alpha \in(0,1) . Z_{t}$ is assumed to follow an exogenous process of the form

$$
\log \left(Z_{t}\right)=\log \left(Z_{t-1}\right)+\gamma_{z}+\sigma_{z} \varepsilon_{z, t}
$$

where $\sigma_{z}>0$ and $\varepsilon_{z, t}$ is iid with zero mean and unit variance. In the terminology of Chari, Kehoe and McGrattan (2004), $Z_{t}^{1-\alpha}$ in the production function corresponds to the efficiency wedge. This wedge may capture for instance input-financing frictions. Capital stock evolves according to the law of motion

$$
K_{t+1}=(1-\delta) K_{t}+I_{t}
$$

where $\delta \in(0,1)$ is a constant depreciation rate. Finally, the final output good can be either consumed or invested

$$
Y_{t}=C_{t}+I_{t}+G_{t}
$$

where $G_{t}$ denotes government consumption. We assume that $g_{t}=G_{t} / Z_{t}$ evolves according to

$$
\log \left(g_{t}\right)=\rho_{g} \log \left(g_{t-1}\right)+\left(1-\rho_{\chi}\right) \log \bar{g}+\sigma_{g} \varepsilon_{g, t}
$$

where $\bar{g}>0,\left|\rho_{g}\right|<1, \sigma_{g}>0$ and $\varepsilon_{g, t}$ is iid with zero mean and unit variance. This shock, labelled government consumption wedge, is for example equivalent to persistent fluctuations in 
net exports in an open economy. The model is thus characterized by three time varying wedges, i.e. the efficiency, labor and government consumption wedges, that summarize a large class of mechanisms without having to explicitly specify them.

To analyze the quantitative implications of the model, we first apply a stationary-inducing transformation for variables that follow a stochastic trend. Output, consumption, investment and government consumption are divided by $Z_{t}$, and the capital stock is divided by $Z_{t-1}$. The approximate solution of the model is computed from a log-linearization of the stationary equilibrium conditions around the deterministic steady state.

The parameter values are familiar from business cycle literature (see Table 1). We set the capital share to $\alpha=0.33$ and the time allocation parameter $\psi=2.5$. We choose the discount factor so that the steady state annualized real interest rate is $3 \%$. We set the depreciation rate $\delta=0.015$. The growth rate of $Z_{t}$, namely $\gamma_{z}$, is equal to 0.0036 . The share of government consumption in total output at steady state is either 0 or $20 \%$, depending on the version of the model we consider. The parameters of the three forcing variables $\left(Z_{t}, G_{t}, \chi_{t}\right)$ are borrowed from previous empirical works with US data. The standard-error $\sigma_{z}$ of the technology shock is equal to 1\% (see Prescott, 1986, Burnside and Eichenbaum, 1996, Chari, Kehoe and McGrattan, 2005 and Christiano, Eichenbaum and Vigfusson, 2005). Following Christiano and Eichenbaum (1992) and Burnside and Eichenbaum (1996), the autoregressive parameter $\rho_{g}$ of government consumption is set to 0.95 . The standard error $\sigma_{g}$ is set to 0.01 or 0.02 . These two values include previous estimates. We choose alternative values $(0.90 ; 0.95 ; 0.99)$ for the autoregressive parameter $\rho_{\chi}$ of the preference shock. Previous estimations (see Chari, Kehoe and McGrattan, 2005 and Christiano, Eichenbaum and Vigfusson, 2005) suggest value between 0.95 and 0.99 , but we add $\rho_{\chi}=0.90$ for a check of robustness. Finally, the standard error of this shock $\sigma_{\chi}$ takes three different values $(0.005 ; 0.01 ; 0.02)$. These values roughly summarize the range of previous estimates (see Erceg, Guerrieri and Gust, 2004, Chari, Kehoe and McGrattan, 2005, and Christiano, Eichenbaum and Vigfusson, 2005). The alternative calibrations summarize previous estimates which use different datasets and estimation techniques. They allow us to conduct a sensitivity analysis and to evaluate the relative merits of different approaches for various calibrations of the forcing variables.

\section{Simulation Results}

In our Monte-Carlo study, we generate 1000 data samples from the business cycle model. Every data sample consists of 200 quarterly observations and corresponds to the typical sample size of 
empirical studies. In order to reduce the effect of initial conditions, the simulated samples include 100 initial points which are subsequently discarded in the estimation. For every data sample, we estimate VAR models with four lags as in Erceg, Guerrieri and Gust (2004), Chari, Kehoe and McGrattan (2005), and Christiano, Eichenbaum and Vigfusson (2005). We consider two versions of the model, depending on the number of shocks included. The two shocks version includes technology shock and preference shocks, whereas the three shocks version adds government consumption. The two shocks version is used so as to evaluate various SVARs with two variables. The three shocks version allows to assess the reliability of three variable SVARs. Moreover, we want to verify if our two step approach properly uncovers the true response of hours when a stationary shock to government consumption affects persistently the consumption to output ratio.

For each experiment, we investigate the reliability of different SVARs based on identification of technology shocks: i) a DSVAR models with labor productivity growth and hours in first difference; ii) a LSVAR model with labor productivity growth and hours in level; iii) CYSVAR$h$ approach in which the SVAR model includes labor productivity growth and consumption to output ratio in the first step and hours are regressed on the estimated technology shock in the second step. The specification of CYSVAR- $\Delta h$ and CYSVAR $-A R(1)$ are the same in the first step, but they consider hours in first difference and lagged hours in the second step (see Section 2 for more details). In the second step of the CYSVAR approach, we consider current and twelve lagged values of the identified (in the first step) technology shocks. ${ }^{9}$

\subsection{Results from the two shock model}

Figures 4 and 5 display the responses of hours for each SVARs in our baseline calibration ( $\rho_{\chi}=0.95$ and $\sigma_{z}=\sigma_{\chi}=0.01$ ). The solid line represents the response of hours in the model, whereas the dotted line corresponds to the estimated response from SVARs.

The response of hours obtained from the DSVAR model displays a large downward bias (see figure 4-(a)), and it is persistently negative. This result is similar to Chari, Kehoe and McGrattan (2005) who show that the difference specification of hours adopted by Galí (1999), Galí and Rabanal (2004) and Francis and Ramey (2004a) can lead to mistaken conclusions about the effect of a technology shock. Note that a DSVAR model is obviously misspecified under the business cycle model considered here, as it implies an over-differentiation of hours. The first difference specification of hours can create distortions and lead to biased estimated responses. However, Chari, Kehoe and McGrattan (2005) show that SVARs with hours in quasi-difference,

\footnotetext{
${ }^{9}$ We also investigate different lagged values of the technology shock and the main results are left unaffected.
} 
consistent with the business cycle model, display similar patterns.

The responses of hours obtained from a LSVAR model displays a large upward bias, as the estimated response on impact is almost twice the true response and is persistently above the true response (see Figure 4-(b)). These results are again in the line with those of Chari, Kehoe and McGrattan (2005) and to a lesser extent similar with those of Christiano, Eichenbaum and Vigfusson (2005). As reported by Chari, Kehoe and McGrattan (2005), confidence intervals with the LSVAR model are very large and therefore not informative. The LSVAR cannot discriminate between a model with a positive or a negative effect of the technology shock on impact. ${ }^{10}$

Consider now the CYSVAR $-h$ approach. Figure 5-(a) shows that this approach delivers reliable estimates of the response of hours. The bias is small, especially in comparison with the ones from the DSVAR and LSVAR. Another interesting result is that the three CYSVAR approaches deliver very similar results (see Figures 5-(a), (b) and (c)). Therefore, our two step approach does not suffer from the specification of hours, contrary to the DSVAR and LSVAR. This result is consistent with Proposition 1. As for the LSVAR, the confidence intervals for CYSVAR $-h$ are large. Interestingly, the confidence intervals for CYSVAR $-\Delta h$ and CYSVARAR(1) are narrower on impact than for the LSVAR model. In particular, an one-sided test rejects the hypothesis that the response on impact is negative at the $5 \%$ level. These two specifications can then reject an alternative model in which hours decreases on impact after a technology improvement. In contrast, as mentioned by Chari, Kehoe and McGrattan (2005), the LSVAR is incapable of differentiating between alternative models with starkly different impulse response functions.

To evaluate the size of the bias, Table 2 reports the cumulative absolute bias between the average response in SVARs and the true response over different horizons. ${ }^{11}$ In this table, we report only simulation results with the CYSVAR-AR(1) approach since these results are invariant to the specification of hours. Our benchmark calibration corresponds to the second panel in Table 2 when $\rho_{\chi}=0.95$ and $\sigma_{\chi} / \sigma_{z}=1$. We also obtained a large bias with DSVAR and LSVAR models (both on impact and for different horizons). However, The CYSVAR-AR(1) delivers very reliable results compared with DSVAR and LSVAR. We also investigate other cal-

\footnotetext{
${ }^{10}$ These very large confidence intervals are not surprising, as long run effects of shocks involve a reliable estimate of the sum of the VAR parameters. The convergence of the least-squares estimator for the VAR does not imply an accurate approximation of the long run effect (see Sims 1972, Faust and Leeper, 1996 and Pötscher, 2002). The lack of precision of the estimated long run effect is then translated to the impulse response functions.

${ }^{11}$ This measure is defined as $c m d(k)=\sum_{i=0}^{k} \mid i r f_{i}($ model $)-i r f_{i}($ svar $) \mid$ where $k$ denotes the selected horizon, $\operatorname{irf} f_{i}$ (model) the RBC impulse response and $\operatorname{irf} f_{i}($ svar $)=(1 / N) \sum_{j=1}^{N} i r f_{i}(\text { svar })^{j}$ the mean of impulse responses over the $N$ simulation experiments obtained from a SVAR model. In fact, the $c m d$ measures the area of the bias up to the horizon $k$.
} 
ibration of $\left(\rho_{\chi}, \sigma_{\chi}\right)$. When the standard error $\sigma_{\chi}$ of the non-technology shock is smaller, the accuracy of the LSVAR and DSVAR models increases (see the cases where $\sigma_{\chi} / \sigma_{z}=0.5$ ) and the LSVAR model and the CSVAR-AR(1) approach deliver very similar results. Conversely, when the standard error $\sigma_{\chi}$ of the preference increases, the LSVAR and DSVAR models poorly identify the effect of a technology shock on hours (see the cases $\sigma_{\chi} / \sigma_{z}=2$ ). In this latter case, the CSVAR approach tends to over-estimate the true effect of the technology shock, but the cumulative absolute mean bias remains small compared to the LSVAR and DSVAR models. Table 2 displays another interesting result: when the persistence of the preference shock increases from 0.9 to 0.99 , the bias decreases. For the DSVAR model, this result can be partly explained by a decrease in distortions created by over-differentiation. For the CYSVAR approach, the bias reduction mainly originates from the effect of the preference shock on hours and consumption to output ratio.

To better understand these last results, we investigate the effect of $\rho_{\chi}$ and $\sigma_{\chi}$ on the structural autoregressive moving average representation of hours and consumption to output ratio. For our baseline calibration $\left(\rho_{\chi}=0.95, \sigma_{z}=\sigma_{\chi}=0.01\right)$, we obtain:

$$
\begin{aligned}
\log \left(H_{t}\right) & =\mathbf{c s t}+0.3536 \frac{1}{(1-0.9622 L)} \sigma_{z} \varepsilon_{z, t}-1.5240 \frac{(1-0.9759 L)}{(1-0.9622 L)(1-0.95 L)} \sigma_{\chi} \varepsilon_{\chi, t} \\
\log \left(C_{t}\right)-\log \left(Y_{t}\right) & =\mathbf{c s t}-0.4220 \frac{1}{(1-0.9622 L)} \sigma_{z} \varepsilon_{z, t}+0.8180 \frac{(1-0.9928 L)}{(1-0.9622 L)(1-0.95 L)} \sigma_{\chi} \varepsilon_{\chi, t},
\end{aligned}
$$

where cst is an appropriate constant. The non-technology component is larger for hours than for consumption to output ratio. In this case, the preference shock accounts for $91 \%$ of variance of hours, whereas it represents $63 \%$ of the variance of the ratio. Moreover, the persistence of hours generated by the preference shock is more pronounced. This can be seen from the $\operatorname{ARMA}(2,1)$ representation of hours and consumption to output ratio. The two series display the same autoregressive parameters, which are associated to the dynamics of capital and the persistence of the preference shock. However, the moving average parameter differs. In the case of hours, the parameter is equal to -0.976 , whereas it is -0.993 for the consumption to output ratio. Figure 6 illustrates this property and reports the autocorrelation function of these two variables due to the preference shock. We see that the autocorrelations of the consumption to output ratio are smaller than the ones of hours. The labor wedge has therefore a greater impact in terms of volatility and persistence on hours than on consumption to output ratio. When the standard error of the preference shock is reduced $\left(\sigma_{\chi}=0.005\right)$, its contribution to the variance decreases, it becomes $73 \%$ for hours and $30 \%$ for the consumption to output ratio. In this case, SVARs have less difficulty to disentangle technology shocks from other shocks that have 
highly persistent, if not permanent effects on labor productivity. This explains why SVARs can properly uncover the true IRFs of hours to a technology shock.

To assess the effect of a highly persistent preference shock, we now set $\rho_{\chi}=0.99$. This situation is of quantitative interest as Christiano, Eichenbaum and Vigfusson (2005) obtain values for this parameter between 0.986 and 0.9994. In this case, the ARMA representation becomes:

$$
\begin{aligned}
\log \left(H_{t}\right) & =\mathbf{c s t}+0.3536 \frac{1}{(1-0.9622 L)} \sigma_{z} \varepsilon_{z, t}-1.2710 \frac{(1-0.9737 L)}{(1-0.9622 L)(1-0.99 L)} \sigma_{\chi} \varepsilon_{\chi, t} \\
\log \left(C_{t}\right)-\log \left(Y_{t}\right) & =\mathbf{c s t}-0.4220 \frac{1}{(1-0.9622 L)} \sigma_{z} \varepsilon_{z, t}+0.5167 \frac{(1-0.9960 L)}{(1-0.9622 L)(1-0.99 L)} \sigma_{\chi} \varepsilon_{\chi, t} .
\end{aligned}
$$

The roots of moving average and the autoregressive parameters related to the preference shock in the expression of the consumption to output ratio are very similar, ${ }^{12}$ so its dynamics can be approximated by a first order autoregressive process:

$$
\left(\log \left(C_{t}\right)-\log \left(Y_{t}\right)\right) \simeq \operatorname{cst}+0.9622\left(\log \left(C_{t-1}\right)-\log \left(Y_{t-1}\right)\right)-0.4220 \sigma_{z} \varepsilon_{z, t}+0.5167 \sigma_{\chi} \varepsilon_{\chi, t} .
$$

The consumption to output ratio behaves like the deflated capital. Conversely, hours do not share this property and finite autoregressions cannot properly uncover its true dynamics. This is illustrated in Figure 7 which reports the autocorrelation function of hours, consumption to output ratio and capital deflated by the total factor productivity. As emphasized by Chari, Kehoe and McGrattan (2005), one of the problem with a SVAR model is that it does not included capitallike variable. In the model, the corresponding relevant state variable is $\log \left(K_{t} / Z_{t-1}\right)$. Since $Z_{t}$ is not observable in practice and $K_{t}$ is measured with errors, we cannot include $\log \left(K_{t} / Z_{t-1}\right)$ in SVARs. As can be seen from Figure 7, the autocorrelation functions of $(C / Y)$ and $(K / Z)$ are very close, but the ones of hours differ sharply.

This latter result suggests that the consumption to output ratio can be a good proxy of the relevant state variable when shocks to labor supply are very persistent or non-stationary. Conversely, hours cannot display this pattern. Highly persistent or non-stationary labor supply shocks is of course debatable but empirical works support this specification in small sample (see Gali, 2005, Christiano, Eichenbaum and Vigfusson, 2005 and Chang, Doh and Schorfheide, 2005). To better understand the results under a close to non-stationary labor supply, we report in appendix $\mathrm{C}$ some calculations about the dynamic behavior of the consumption to output ratio

\footnotetext{
${ }^{12}$ When we set $\rho_{\chi}=0.999$, this finding is strengthened. Regarding only the effect of the preference shock, the reduced form of the consumption to output ratio is $\log \left(C_{t}\right)-\log \left(Y_{t}\right)=0.3733(1-0.9993 L)(1-0.9622 L)^{-1}(1-$ $0.999 L)^{-1} \sigma_{\chi} \varepsilon_{\chi, t}$.
} 
and hours for an economy with non stationary labor supply shocks. We notably show that when preference shocks follow a random walk (and thus hours are non-stationary), the consumption to output ratio follows an autoregressive process of order one with an autoregressive parameter exactly equal to the one of the deflated capital. Conversely, the growth rate of hours follows an ARMA process which can be poorly approximated by finite autoregressions. Note that a SVAR model with long-run restrictions that includes labor productivity growth and the consumption to output ratio is valid whatever the process (stationary or non-stationary) of the hours series. The CYSVAR approach allows us to abstract from the very sensitive specification choice of hours in SVARs.

Simulation results for the cumulative absolute bias are completed with a measure of uncertainty about the estimated effect of the technology shocks. We thus compute the cumulative Root Mean Square Errors (RMSE) at various horizons. ${ }^{13}$ The RMSE accounts for both bias and dispersion of the estimated IRFs. The results are reported in Table 3. Simulation experiments for different calibrations show again that the CSVAR approach provides smaller RMSE than the LSVAR and DSVAR models. This result comes essentially from the smaller bias with CSVAR. The large RMSE of DSVAR mainly originates from the large bias. In consequence, DSVAR model displays IRFs that are strongly biased but more precisely estimated. In contrast, LSVAR model displays smaller bias of IRFs but larger dispersion than DSVAR. The CSVAR approach presents the smallest bias on estimated IRFs and the estimated responses are more precisely estimated in comparison with LSVAR. These results from RMSE suggest favoring CYSVAR to LSVAR and DSVAR.

Finally, to judge the identification of the structural shocks, we compute the correlation between the estimated shock and the true shock of the various version of the business cycle model. More precisely, we first compute the correlation between the estimated (from SVARs) and the true technology shocks, namely: $\operatorname{Corr}\left(\varepsilon_{z}, \boldsymbol{\eta}^{T}\right)$, where $\varepsilon_{z}$ denotes the true technology shock and $\boldsymbol{\eta}^{T}$ is the estimated technology shock from SVARs. We also compute $\operatorname{Corr}\left(\varepsilon_{\chi}, \boldsymbol{\eta}^{T}\right)$, the correlation between the estimated technology shock and non-technology shock $\varepsilon_{\chi}$ of the business cycle model. The idea is that if any method is able to consistently estimate the technology shock, we must obtain $\operatorname{Corr}\left(\varepsilon_{z}, \boldsymbol{\eta}^{T}\right) \approx 1$ and $\operatorname{Corr}\left(\varepsilon_{\chi}, \boldsymbol{\eta}^{T}\right) \approx 0$. These correlations are reported in Table 4. The CYSVAR approach always delivers the highest $\operatorname{Corr}\left(\varepsilon_{z}, \boldsymbol{\eta}^{T}\right)$. This correlation is relatively high, as it always exceeds 0.9 and it is not very sensitive to changes in $\left(\sigma_{z}, \rho_{\chi}, \sigma_{\chi}\right)$. Conversely,

\footnotetext{
${ }^{13}$ This measure is defined as crmse $(k)=\sum_{i=0}^{k} r_{m s e}$ where $k$ denotes the selected horizon, $r m s e_{i}=$ $\left((1 / N) \sum_{j=1}^{N}\left(\operatorname{irf} f_{i}(\text { model })-i r f_{i}(s v a r)^{j}\right)^{2}\right)^{1 / 2}$ the RMSE at horizon $i$, irf $f_{i}$ (model) the RBC impulse response function of hours and $\operatorname{irf} f_{i}(s v a r)^{j}$ the $S V A R$ impulse responses function of hours for the $j^{\text {th }}$ draw and $N$ is the number of simulation experiments.
} 
this correlation is lower in the case of the DSVAR model and it decreases dramatically with the volatility of the preference shock. For example, when $\sigma_{\chi}=2 \sigma_{z}$ and $\rho_{\chi}=0.99$, the correlation is 0.65 for the DSVAR model, in comparison with 0.91 for the CYSVAR approach. The LSVAR delivers better results that the DSVAR, but it never outperforms the CYSVAR approach.

Let us now examine the correlation between the identified technology shocks of the true preference shocks, namely: $\operatorname{Cor}\left(\varepsilon_{\chi}, \boldsymbol{\eta}^{N T}\right)$. The CYSVAR approach always delivers the lowest correlation (in absolute value). In the case of the DSVAR model, this correlation becomes large $\left(\operatorname{Corr}\left(\varepsilon_{\chi}, \boldsymbol{\eta}^{T}\right) \approx 0.72\right)$ when the variance of the preference shock increases. The large correlation allows to explain why the DSVAR model estimates a negative response of hours to a technology shock. Indeed, the estimated technology shock is contaminated by the preference shock. Hours worked persistently decrease after this shock in the model. It follows that the DSVAR model erroneously concludes that hours drop after a technology shock. A similar result applies in the case of the LSVAR model: the correlation between the estimated technology shock and the true non-technology shock is negative. ${ }^{14}$. This explains why the LSVAR model over-estimates the effect of a technology shock. In contrast, the CYSVAR approach does not suffer from this contamination.

\subsection{Results from the three shock model}

We first investigate the reliability of SVARs which include two variables (labor productivity and hours for LSVAR and DSVAR models; labor productivity and consumption to output ratio for our two step approach). Figure 8 displays the responses of hours for each SVAR using our baseline calibration $\left(\rho_{\chi}=\rho_{g}=0.95, \sigma_{z}=\sigma_{\chi}=\sigma_{g}=0.01\right)$. As in the case of two shocks, the response of hours obtained from the DSVAR model is downward biased (see Figure 8-(a)) and persistently negative. The response of hours from the LSVAR model is upward biased and the CYSVAR approach delivers again more reliable results. This is confirmed in the first panel of Table 5. For the two values of $\sigma_{g}=(0.01 ; 0.02)$, the CYSVAR approach outperforms the DSVAR and LSVAR models. Notice that increasing the size of the government consumption shock does not deteriorate the reliability of the two step approach.

From our three shock model, we assess the DSVAR and LSVAR when they include three variables (labor productivity, hours and consumption to output ratio). Figure 9 reports the responses of hours for the three approaches. Figures 9-(a) and 9-(b) show that SVAR models that include three variables deliver better results. The downward bias of the DSVAR is reduced, as the response on impact becomes positive. Moreover, the upward bias of the LSVAR decreased.

\footnotetext{
${ }^{14}$ When $\sigma_{\chi}=2 \times \sigma_{z}$, the LSVAR model provides $\operatorname{Corr}\left(\varepsilon_{\chi}, \boldsymbol{\eta}^{T}\right) \approx-0.40$.
} 
However, the DSVAR and LSVAR models do not uncover the true response of hours. These results are in the line with those of Chari, Kehoe and McGrattan (2005). In our experiments, the CYSVAR approach largely outperforms the DSVAR and LSVAR models (see Table 5). At a first glance, this result is surprising, as a SVAR model which includes labor-productivity and consumption to output ratio (CYSVAR) must a priori contain the same information as a SVAR with labor-productivity, hours and consumption to output ratio (LSVAR). Our findings mainly originate in the fact that finite order autoregression cannot properly represent the time series behavior of hours as implied by the model. It follows that hours in SVAR contaminates the estimation of IRFs, even if the consumption to output ratio is included in the VAR model. These results suggest eliminating hours from SVAR models if the objective is to consistently identify technology shocks.

We also report in Table 6 the correlation between the estimated technology shock and the true shock of the business cycle model. We do not report the correlation with individual stationary shocks as we cannot separately identify each of them. The CYSVAR approach delivers again the highest $\operatorname{Corr}\left(\varepsilon_{z}, \boldsymbol{\eta}^{T}\right)$. This correlation is relatively high, as it always exceeds 0.9 and it is not very sensitive to changes in $\sigma_{g}$. Conversely, the LSVAR model with three variables provides the lowest correlation, around 0.83. Interestingly, the DSVAR model with three variables performs better than the DSVAR with two variables as the correlation increases from 0.77 to 0.91 .

Finally, we evaluate the relative performance of our approach in comparison with the LSVAR and DSVAR models which use the alternative nonparametric estimator of the long-run covariance matrix proposed by Christiano, Eichenbaum and Vigfusson (2005). In most cases, the CYSVAR approach still outperforms the LSVAR and DSVAR models. We decide not to report those results because the use of this alternative estimator raises two problems. First, this way of proceed is not conceptually consistent with the fundamental relation between the structural and the reduced form. Indeed, the estimator of the matrix $\mathbf{A}_{\mathbf{0}}$ allowing to retrieve the structural shocks from the reduced form shocks does not respect the following relation $\mathbf{A}_{\mathbf{0}} \mathbf{A}_{\mathbf{0}}{ }^{\prime}=\boldsymbol{\Sigma}$ between the structural and the reduced forms. Consequently, it seems to us very difficult to interpret such results. Second, the bandwidth parameter is arbitrarily fixed to 150 for a sample of 180 observations (!!!). Such estimator of the long run covariance matrix needs to fulfill conditions to be consistent. In particular, the bandwidth parameter for the Bartlett kernel needs to grow at a rate which does not exceed $T^{1 / 3}$ where $T$ is the number of observations. ${ }^{15}$ This condition is clearly violated

\footnotetext{
${ }^{15}$ Alternative consistent data-driven procedure to choose the bandwidth parameter can be used as proposed by Newey and West (1994), among others.
} 
for a bandwidth parameter equals to 150 , consequently their estimator is not consistent. ${ }^{16}$

\section{Application of the Two Step Approach}

We first present our empirical results with the two step approach. Second, we investigate the effects of breaks in labor productivity.

\subsection{Findings}

We now apply our methodology to US data (see the first section). We first estimate a bivariate VAR model with four lags that includes productivity growth and the log of consumption to output ratio. We then identify the technology shock using the long run restriction that only this shock can have a long run effect on labor productivity. Technology shock leads to a permanent increase in labor productivity, while the consumption to output ratio decreases in the short run, illustrating the smoothness of consumption. As pointed out by Francis and Ramey (2004a), an important issue concerns the response of labor productivity to the non-technology shock. Francis and Ramey (2004a) show that the impulse response functions from LSVAR model indicate that non-technology shocks have a very persistent and significant effect on labor productivity. The estimated responses from LSVAR are thus inconsistent with the fundamental identifying assumption. In contrast, the DSVAR specification used by Galí (1999) and Francis and Ramey (2004a) does not display this pattern. With the CYSVAR model, the response of labor productivity to a non-technology shock is short-lived as it vanishes after 12 periods and is statistically not different from zero after three periods. Our approach is thus consistent with the basic identifying assumption that this shock cannot have a permanent effect on labor productivity. This is again a direct consequence of the use of the consumption to output ratio instead of hours in the SVAR model.

Using the estimated value of the technology shock, we estimate the response of hours by OLS regressions. We consider the specification CYSVAR $-A R(1)$. The impulse response functions, as well as their $95 \%$ confidence intervals, are reported in Figure 10. The confidence intervals are computed using the formula presented in Appendix B. On impact, hours worked decrease after a technology shock. After three periods, the response becomes persistently positive and

\footnotetext{
${ }^{16}$ As shown in the simulations, the LSVAR overestimates the impact effect of the technology on hours worked. For a choice of the bandwidth parameter too large, the nonparametric estimator of the spectral density at zero frequency with the Bartlett window is known to be downward biased (see Hauser, Pötscher, and Reshenhofer, 1999). For this reason, the choice of a bandwidth equal to 150 decreases the bias of the estimated impact in the simulations. However, for an economy with only the technology and the government spending shocks, the standard LSVAR underestimates the impact of the technology on hours worked. In this case, the procedure using the nonparametric estimator with 150 lags amplifies the underestimation of the impact effect which is consistent with the downward bias of this estimator for a large bandwidth as mentioned above.
} 
hump-shaped. The 95\% confidence interval suggests that the response of hours on impact is significantly different from zero. However, the positive hump-shaped response of hours is not precisely estimated.

The shape of the response of hours is very similar to what Basu, Fernald and Kimball (2004) obtain with US annual data. Our first step differs from theirs, as we use a SVAR model with a long-run restriction, whereas they construct a measure of aggregate technology change, controlling for imperfect competition, varying utilization of factors and aggregation effects. However, our second step shares the same methodology since the effect of technology improvement is measured by a simple regression of hours on lags of itself and the estimated technology shock. ${ }^{17}$ They find that total hours worked fall significantly on impact. During the subsequent years, hours recover sharply. However, the response of hours is not precisely estimated, except on impact. Our results suggest a significant negative effect of technology improvement in the very short-run and a delay but not significant positive effect. Our findings are also similar to what Francis and Ramey (2004b) obtains for the period 1949-2002 with their demographic-adjusted measure of hours per capita. Using three specifications of hours (level, detrended and first difference), Francis and Ramey (2004b) find that following a positive technology shock, hours worked decrease on impact but increase after two periods. Nevertheless, the effect of a technology shock does not appear significant, with the exception of the first difference specification of hours in the very short run. Our findings are also in line with those of Uhlig (2004), Vigfusson (2004) and Pesavento and Rossi (2005). For example, we find a large and delayed response of hours after a technology shock as in Vigfusson (2004). Vigfusson obtains a hump after ten quarters with constructed productivity series and hours in level, while our two step estimation suggests a hump around seven quarters. Moreover, the magnitude of the response at the hump is very similar (around 0.3).

\subsection{Breaks in Labor Productivity}

We investigate the sensitivity of our results to structural breaks in labor productivity. Fernald (2004) shows that once we allow for trend breaks in labor productivity, the response of hours to a technology shock in LSVAR becomes negative. The breaking dates identified by Fernald are 1973Q1 and 1997Q2. Using the data of Section 1 on the non-farm business sector, we first regress labor productivity growth on a constant, a pre-1973Q1 dummy variable and a pre-1997Q1 dummy variable. We then use the residuals of this regression as a new measure of labor productivity growth. We estimate the bivariate VAR model with a level specification

\footnotetext{
${ }^{17}$ As in Basu, Fernald and Kimball (2004), we account for generated regressors.
} 
of hours (LSVAR) and compute the response of hours to a technology shock. The response of hours is reported in Figure 11-(a). Contrary to Figure 2-(a), the response of hours is now negative. The LSVAR specification appears very sensitive to the low-frequencies components of labor productivity growth. ${ }^{18}$ Following Fernald (2004), the positive response of hours in LSVAR can be attributed to the productivity post-1973 slowdown and the late-1990s productivity acceleration. Nevertheless, Figure 11-(a) shows that the estimated response is not precisely estimated, except on impact where the negative response is significantly different from zero.

We apply the same methodology to our two step approach. In the fist step, we first estimate a bivariate VAR that includes the new measure of labor productivity growth and consumption to output ratio. We estimate the technology shock using long-run restriction and we compute the response of hours from a linear regression of hours on one lag of itself and the technology shock (CYSVAR-AR(1) specification) in the second step. The response of hours to a technology shock is reported in Figure 11-(b). The response appears slightly affected as the negative response on impact is a bit more pronounced (see Figure 10 for a comparison). However, the hump-shaped and delayed-positive response is maintained. When we allow for structural breaks in labor productivity and thus remove low frequencies components in this variable, the CYSVAR-AR(1) yields more precise estimates of the impulse response functions of hours for the first four periods. Our estimation of the effect of a technology shock are again in the line with the one obtained by Basu, Fernald and Kimball (2004) and Vigfusson (2004).

\section{Conclusion}

This paper proposes a simple two step approach to consistently estimate a technology shock and the response of hours worked that follows a technology improvement. In a first step, a SVAR model with labor productivity growth and consumption to output ratio allows us to estimate the technology shock. In a second step, the response of hours is obtained by a simple regression of hours on the estimated technology shock.

Our approach is motivated by the dynamics of labor productivity and hours which are poorly approximated by finite autoregressions. When placed in a SVAR, this leads to a large bias in the estimated structural shocks and misleading conclusions about the aggregate effect of a technology shock. When applied to artificial data generated by a standard business cycle model, our approach replicates more closely the model impulse response functions. The estimated technology shock is highly correlated with the true one and the correlation with the non-technology

\footnotetext{
${ }^{18}$ Conversely, Fernald (2004) show that the DSVAR is less sensitive to breaks in labor productivity growth. We obtain similar results with our data.
} 
shock is very small. Moreover, the results are invariant to the specification of hours in level or in difference.

The two step approach, when applied on actual data, predicts a short-run decrease of hours after a technology improvement, as well as a delayed and hump-shaped positive response. Our findings are in accordance with those of Basu, Fernald and Kimball (2004) and Vigfusson (2004). Moreover, allowing for breaks in labor productivity growth as in Fernald (2004) does not alter this result.

The proposed approach is devoted to the estimation of the response of hours worked. However, this approach can be easily used in order to evaluate the effect of a technology improvement on other aggregate variables. The hours worked only needs to be replaced by another variable of interest (output, investment, wages, prices,...) in the second step. 


\section{References}

Andrews, D.W.K. and J.C. Mohanan (1992) "An Improved Heteroskedasticidy and Autocorrelation Consistent Covariance Matrix Estimator", Econometrica, 60, 953-966.

Basu, S., Fernald, J. and M. Kimball (2004) "Are Technology Improvements Contractionary?", forthcoming American Economic Review.

Bernanke, B. (1986) "Alternative Explorations of the Money-Income Correlation," in: Brunner, Karl and Allan H. Meltzer, eds., Real Business Cycles, Real Exchange Rates, and Actual Policies, Carnegie-Rochester Conference Series on Public Policy, 25, pp. 49-99.

Blanchard, O.J. and D. Quah (1989) "The Dynamic Effects of Aggregate Demand and Supply Disturbances" , American Economic Review, 79(4), pp. 655-673.

Burnside, C. and M. Eichenbaum (1996) "Factor-Hoarding and the Propagation of BusinessCycle Shocks", American Economic Review, 86(5), pp. 1154-1174.

Chang, Y., Doh, T. and Schorfheide, F. (2005) "Non-stationary Hours in a DSGE Model", CEPR Discussion Paper 5232.

Chang, Y. and Hong, J. H. (2005) "Do Technological Improvements In The Manufacturing Sector Raise or Lower Employment?", forthcoming American Economic Review.

Chari, V., Kehoe, P. and E. Mc Grattan (2004) "Business Cycle Accounting", Federal Reserve Bank of Minneapolis, Research Department Staff Report 328.

Chari, V., Kehoe, P. and E. Mc Grattan (2005) "A Critique of Structural VARs Using Real Business Cycle Theory", Federal Reserve Bank of Minneapolis, Research Department Staff Report 364 .

Christiano, L. and M. Eichenbaum (1992) "Current Real-Business-Cycle Theories and Aggregate Labor-Market Fluctuations", American Economic Review, 82(3), pp. 430-450.

Christiano, L., Eichenbaum, M. and R. Vigfusson (2004) "What Happens after a Technology Shock", NBER Working Paper Number 9819, revised version 2004.

Christiano, L., Eichenbaum, M. and R. Vigfusson (2005) "Assessing Structural VARs", preliminary draft, Northwestern University.

Cochrane, J. (1994) "Permanent and Transitory Components of GDP and Stock Returns", Quarterly Journal of Economics, 109(1), pp. 241-266. 
Cooley, T. and S. LeRoy (1985) "Atheoretical Macroeconometrics: A Critique." Journal of Monetary Economics, 16, pp. 283-308.

Cooley, T. and M. Dwyer (1998) "Business Cycle Analysis without Much Theory: A Look at Structural VARs", Journal of Econometrics, 83(1-2), pp. 57-88.

Erceg, C., Guerrieri, L. and C. Gust (2005) "Can Long-Run Restrictions Identify Technology Shocks", Board of Governors of the Federal Reserve System, International Finance Discussion paper, Number 792, updated version, forthcoming Journal of European Economic Association.

Faust, J. and E.M. Leeper (1997) "When Do Long-Run Identifying Restrictions Give Reliable Results?", Journal of Business 85 Economic Statistics, 15(3), pp. 345-353.

Fernald, J. (2004) "Trend Breaks, Long Run Restrictions, and the Contractionary Effects of Technology Shocks44, Manuscript, Federal Reserve Bank of Chicago.

Francis, N. and V. Ramey (2004a) "Is the Technology-Driven Real Business Cycle Hypothesis Dead? Shocks and Aggregate Fluctuations Revisited", forthcoming Journal of Monetary Economics.

Francis, N. and V. Ramey (2004b) "The source of Historical Economic Fluctuations: an Analysis Using Long-Run Restrictions", forthcoming NBER International Seminar on Macroeconomics, eds R. Clarida, J. Frankel, and Fransesco Giavazzi.

Francis, N., Owyang, M. and J. Roush (2005) "A Flexible Finite-Horizon Identification of Technology Shocks", , Board of Governors of the Federal Reserve System, International Finance Discussion Paper 832, april.

Galí, J. (1999) "Technology, Employment and the Business Cycle: Do Technology Shocks Explain Aggregate Fluctuations?", American Economic Review, 89(1), pp. 249-271.

Galí, J. (2005) "Trends in Hours, Balanced Growth and the Role of Technology in the Business Cycle", Federal Reserve Bank of Saint Louis Review, 87(4), pp. 459-486.

Galí, J., and P. Rabanal (2004) "Technology Shocks and Aggregate Fluctuations; How Well does the RBC Model Fit Postwar U.S. Data?", forthcoming NBER Macroeconomics Annual.

Hall, R. (1997) "Macroeconomic Fluctuations and the Allocation of Time", Journal of Labor Economics, 15(1), pp. 223-250.

Hansen, L. (1982) "Large Sample Properties of Generalized Method of Moments", Econometrica, 50, pp. 1029-1054. 
Hauser, M. A., B.M. Pötscher and Reschenhofer (1999), "Measuring Persistence in Aggregate Output: ARMA Models, Fractionally Integrated ARMA Models and Nonparametric Procedures ", Empirical economics, 24, pp. 243-269.

Kwiatkowski D., Phillips P.C.B., Schmidt P. and Y. Shin (1992) "Testing the Null Hypothesis of Stationarity Against the Alternative of Unit Root", Journal of Econometrics, 54, pp. 159-178.

Lewis, R. and G.C. Reinsel (1985) "Prediction of Multivariate Time Series by Autoregressive Model Fitting", Journal of Multivariate Analysis, 15(1), pp. 393-411.

Newey, W.K. (1984) "A Method of Moments Interpretation of Sequential Estimators ", Economics Letters, 14, pp. 201-206.

Newey, W.K. and K. West (1994) "Automatic Lag Selection in Covariance Matrix Estimation", Review of Economic Studies, 61, pp. 631-653.

Pötscher, B. M. (2002), "Lower Risks Bounds and Properties of Confidence Sets for Ill-Posed Estimation Problems with Applications to Spectral Density and Persistence Estimation, Unit Roots, and Estimation of Long Memory Parameters ", Econometrica, 70(3), pp. 1035-1065.

Pesavento, E. and B. Rossi (2005) "Do Technology Shocks Drive Hours Up or Down", forthcoming Macroeconomic Dynamics.

Sims, C. (1972) "The Role of Approximate Prior Restrictions in Distributed Lag Estimation", Journal of American Statistical Association, vol. 67, pp. 169-175.

Uhlig, H. (2004) "Do Technology Shocks Lead to a Fall in Total Hours Worked?", Journal of European Economic Association, vol. 2, 2-3, pp. 361-371.

Vigfusson R. (2004) "The Delayed Response to a Technology Shock. A Flexible Price Explanation", Board of Governors of the Federal Reserve System, International Finance Discussion Paper 810, july. 


\section{Appendix}

\section{A Proof of Proposition 1}

The consistency of the second step estimators depends on the consistency of the autoregressive coefficients in the first step. The consistency of the the autoregressive coefficients ensures the consistency of the estimated technology shocks. Two cases are of interest: i) the data are generated by a finite VAR or ii) the data are generated by an infinite VAR. When the data are generated by a finite VAR, the VAR estimators in the first step are consistent for a number of lags included in the VAR greater or equal to the true ones. For data generated by an infinite VAR, Lewis and Reinsel (1983) show that a finite order $k$ fitted VAR to a realization $T$ provides consistency and asymptotic normality of the estimated autoregressive coefficients assuming that $k \rightarrow \infty$ at some rate as $T \rightarrow \infty$. In particular, they show the consistency for $k$ function of $T$ such that $k^{2} / T \rightarrow 0$ as $k, T \rightarrow \infty$.

Now, consider the first specification in the second step. The convergence in probability is established by standard arguments. First, the estimator $\widehat{a}_{21, k}$ is centered to the true value by direct straightforward implications of the orthogonality of the permanent and the transitory shocks and by the fact that those shocks are serially uncorrelated. Second, it is easy to show that the variance of the OLS estimator converges to zero. The convergence in probability follows.

Let us now examine the second and the third specifications. We need to suppose that the infinite moving average representation can be rewritten as follows:

$$
h_{t}-\tilde{\rho} h_{t-1}=\boldsymbol{\theta}_{21}(L) \boldsymbol{\eta}_{t}^{T}+\boldsymbol{\theta}_{22}(L) \boldsymbol{\eta}_{t}^{N T}
$$

The structural moving average coefficients can thus be retrieved by $a_{21, k}=\sum_{j=0}^{k} \tilde{\rho}^{j} \theta_{21, k-j}$. We can easily see that for a given bounded $\tilde{\rho}$, a consistent estimator of $\widehat{a}_{21, k}$ is obtained if and only if the OLS estimator of $\hat{\theta}_{21, k}$ converges in probability to $\theta_{21, k}$. The consistency of $\hat{\theta}_{21, k}$ is guaranteed by the same arguments expressed above. For the second specification, $\tilde{\rho}$ is considered fixed to 1 , the OLS estimators $\hat{a}_{21, k}$ are then consistent. For the third specification, one only needs to suppose that the OLS estimator of $\tilde{\rho}$ is bounded in probability, namely $\sqrt{T}(\hat{\rho}-\tilde{\rho})=O_{p}(1)$ for some $\tilde{\rho} \in \mathbb{R}$ (see Andrews and Mohanan (1992) for a similar argument in a different context). 


\section{B Computation of the estimator for the asymptotic covariance matrix in our two step approach}

Following Newey (1984), a sequential two step estimators can be viewed as being obtained from solving a set of moment conditions with a recursive structure. First consider a method of moment estimator based on the population moment conditions

$$
E\left[f\left(x_{t}, \beta_{0}\right)\right]=0 .
$$

The corresponding empirical moment conditions

$$
\frac{1}{T} \sum_{t=1}^{T}\left[f\left(x_{t}, \beta\right)\right],
$$

can be used to obtain a method of moments estimator $\widehat{\beta}$ by setting these sample moments as close as possible to zero (see Hansen, 1982).

Now, consider the partition of the parameter vector $\beta$ as $\beta=\left(\theta^{\prime}, \lambda^{\prime}\right)^{\prime}$ so that

$$
f\left(x_{t}, \beta\right)=\left(g\left(x_{t}, \theta\right)^{\prime}, h\left(x_{t}, \theta, \lambda\right)^{\prime}\right)^{\prime}
$$

where $g\left(x_{t}, \theta\right)$ and $h\left(x_{t}, \theta, \lambda\right)$ are respectively the corresponding population moment conditions of the first and the second step estimations. In our application, $g\left(x_{t}, \theta\right)$ is given by the orthogonality conditions of the VAR, namely:

$$
g\left(x_{t}, \theta\right)=\mathcal{Z}_{t-1} \otimes \varepsilon_{t}(\theta)
$$

where $\mathcal{Z}_{t-1}$ is a vector which includes a constant and the lagged values up to order four of labor productivity in difference and consumption to output ratio. The second set of moment conditions $h\left(x_{t}, \theta, \lambda\right)$ corresponds to the orthogonality conditions of the OLS estimation given by

$$
h\left(x_{t}, \theta, \lambda\right)=W_{t}(\theta) \times \nu_{t}(\theta, \lambda)
$$

where the vector $W_{t}(\theta)$ contains a constant, the identified technology shocks in the first-step which depends on $\theta$ and a lagged value of the hours series if included.

Let now defines $F=E\left[f_{\beta}\left(x_{t}, \beta_{0}\right)\right]$ as the derivative of the population moment conditions respective the the true parameter vector $\beta_{0}$ and $V=E\left[f\left(x_{t}, \beta_{0}\right) f\left(x_{t}, \beta_{0}\right)^{\prime}\right]$ as the covariance matrix of the population moment conditions evaluated at the true value $\beta_{0}$. Let partition $F$ and $V$ be conformable with $\beta$ and $f\left(x_{t}, \beta\right)$, so that,

$$
F=\left[\begin{array}{cc}
G_{\theta} & 0 \\
H_{\theta} & H_{\lambda}
\end{array}\right]
$$


and

$$
V=\left[\begin{array}{ll}
V_{g g} & V_{g h} \\
V_{h g} & V_{h h}
\end{array}\right]
$$

with, for example, $H_{\theta}=E\left[\partial h\left(x_{t}, \theta_{0}, \lambda_{0}\right) / \partial \theta\right]$ and $V_{g h}=\left[g\left(x_{t}, \theta_{0}\right) h\left(x_{t}, \theta_{0}, \lambda_{0}\right)^{\prime}\right]$.

Newey (1984) shows that the asymptotic covariance matrix of the second step estimator is given by the following expression:

$\Omega_{\lambda}=H_{\lambda}^{-1} V_{h h} H_{\lambda}^{-1} \prime+H_{\lambda}^{-1} H_{\theta}\left[G_{\theta}^{-1} V_{g g} G_{\theta}^{-1} \prime\right] H_{\theta} H_{\lambda}^{-1} \prime-H_{\lambda}^{-1}\left[H_{\theta} G_{\theta}^{-1} V_{g h}+V_{h g} G_{\theta}^{-1} H_{\theta^{\prime}}\right] H_{\lambda}^{-1}$

The first term of this expression corresponds to the usual covariance matrix of second step estimators. The second and the third terms correct for the generated regressors problem involved in the first step estimation.

A consistent estimator of the asymptotic covariance matrix can be obtained with a consistent estimator of each terms. For the VAR at the first step with a sufficient number of lags, the moment conditions corresponding to this step are serially uncorrelated, the variance covariance matrix is thus given by an estimator of $\Sigma \otimes \mathcal{Z}_{t-1}^{\prime} \mathcal{Z}_{t-1}$. We can also easily show that the estimator of the terms $V_{g h}$ and $V_{h g}$ does not need be adjusted for serial correlation. A consistent estimator of the asymptotic covariance matrix of the second step moments conditions $V_{h h}$ which are probably serially correlated can be obtained with the usual Newey and West (1994) estimator. 


\section{A Business Cycle Model with Non-Stationary Hours}

In this appendix, we present a simple business cycle model wherein hours are non-stationary due to permanent preference shocks (see Chang, Doh and Schorfheide, 2005).

\section{C.1 The Model}

The model includes a random walk in productivity $\left(Z_{t}\right)$ and non-stationary hours, due to a permanent preference shock $\left(B_{t}\right)$. The intertemporal expected utility function of the representative household is given by

$$
E_{t} \sum_{i=0}^{\infty} \beta^{i}\left\{\log \left(C_{t+i}\right)-\chi\left(H_{t+i} / B_{t+i}\right)\right\},
$$

where $\chi>0, \beta \in(0,1)$ denotes the discount factor and $E_{t}$ is the expectation operator conditional on the information set available as of time $t . C_{t}$ is the consumption at $t$ and $H_{t}$ represents the household's labor supply. The labor supply is subjected to a preference shock $B_{t}$, that follows the stochastic process $\Delta \log \left(B_{t}\right)=\sigma_{b} \varepsilon_{b, t}$, where $\sigma_{b}>0$, and $\varepsilon_{b, t}$ is iid with zero mean and unit variance. The representative firm uses capital $K_{t}$ and labor $H_{t}$ to produce the homogeneous final good $Y_{t}$. The technology is represented by the following constant returns-to-scale Cobb-Douglas production function

$$
Y_{t}=K_{t}^{\alpha}\left(Z_{t} H_{t}\right)^{1-\alpha}
$$

where $\alpha \in(0,1) . Z_{t}$ is assumed to follow an exogenous process of the form $\Delta \log \left(Z_{t}\right)=\sigma_{z} \varepsilon_{z, t}$, where $\varepsilon_{z, t}$ is iid with zero mean and unit variance. The capital stock evolves according to the law of motion

$$
K_{t+1}=(1-\delta) K_{t}+I_{t}
$$

where $\delta \in(0,1)$ is the constant depreciation rate. Finally, the final good can be either consumed or invested

$$
Y_{t}=C_{t}+I_{t}
$$

In this model, the labor supply shock $B_{t}$ induces a stochastic trend into hours as well as into output, consumption, and capital. In addition, $Z_{t}$ has a long-run impact on $Y_{t}, C_{t}, K_{t}$, and $I_{t}$. Accordingly, to obtain a stationary equilibrium, these variables must be detrended as follows

$$
\breve{h}_{t}=\frac{H_{t}}{B_{t}}, \quad \breve{y}_{t}=\frac{Y_{t}}{Z_{t} B_{t}}, \quad \breve{c}_{t}=\frac{C_{t}}{Z_{t} B_{t}}, \quad \breve{i}_{t}=\frac{I_{t}}{Z_{t} B_{t}}, \quad \breve{k}_{t+1}=\frac{K_{t+1}}{Z_{t} B_{t}} .
$$

With these transformations, the approximate solution of the model is computed from a loglinearization of the stationary equilibrium conditions around this deterministic steady state. It is important to notice that in our model, $B_{t}$ has a long-run impact on $H_{t}$, as well as on $Y_{t}$ and 
the above trending variables. At the same time, $Z_{t}$ alone can have a long-run effect on labor productivity. Hence, this model is perfectly compatible with the identification assumptions used by Galí (1999).

\section{C.2 Approximate Solution}

The $\log$-linearization of equilibrium conditions around the deterministic steady state yields

$$
\begin{aligned}
\widehat{\breve{k}}_{t+1} & =(1-\delta)\left(\widehat{\breve{k}}_{t}-\sigma_{z} \varepsilon_{z, t}-\sigma_{b} \varepsilon_{b, t}\right)+\frac{y}{k} \widehat{\breve{y}}_{t}-\frac{c}{k} \widehat{\breve{c}}_{t} \\
\widehat{\breve{h}}_{t} & =\widehat{\breve{y}}_{t}-\widehat{\breve{c}}_{t} \\
\widehat{\breve{y}}_{t} & =\alpha\left(\widehat{\breve{k}}_{t}-\sigma_{z} \varepsilon_{z, t}-\sigma_{b} \varepsilon_{b, t}\right)+(1-\alpha) \widehat{\breve{h}}_{t} \\
E_{t} \widehat{\breve{c}}_{t+1} & =\widehat{\breve{c}}_{t}+\alpha \beta \frac{y}{k} E_{t}\left(\widehat{\breve{y}}_{t+1}-\widehat{\breve{k}}_{t+1}-\sigma_{z} \varepsilon_{z, t+1}-\sigma_{b} \varepsilon_{b, t+1}\right)
\end{aligned}
$$

where $y / k=(1-\beta(1-\delta)) /(\alpha \beta)$ and $c / k=y / k-\delta$. After substitution of (9) into (10), one gets

$$
\widehat{\breve{y}}_{t}-\widehat{\breve{k}}_{t}=-\sigma_{z} \varepsilon_{z, t}-\sigma_{b} \varepsilon_{b, t}-\frac{1-\alpha}{\alpha} \widehat{\breve{c}}_{t}
$$

Now, using the above expression, (8) and (11) rewrite

$$
\begin{aligned}
E_{t} \widehat{\breve{c}}_{t+1} & =\varphi \widehat{\breve{c}}_{t} \quad \text { with } \quad \varphi=\frac{\alpha}{1-\beta(1-\alpha)(1-\delta)} \in(0,1) \\
\widehat{\breve{k}}_{t+1} & =\nu_{1} \widehat{\breve{k}}_{t}-\nu_{1}\left(\sigma_{z} \varepsilon_{z, t}+\sigma_{b} \varepsilon_{b, t}\right)-\nu_{2} \widehat{\breve{c}}_{t} \\
& \quad \text { with } \nu_{1}=\frac{1}{\beta \varphi}>1 \quad \text { and } \quad \nu_{2}=\frac{1-\beta\left(1-\delta\left(1-\alpha^{2}\right)\right)}{\alpha^{2} \beta}
\end{aligned}
$$

As $\nu_{1}>1,(13)$ must be solved forward

$$
\widehat{\breve{k}}_{t}=\sigma_{z} \varepsilon_{z, t}+\sigma_{b} \varepsilon_{b, t}+\left(\frac{\nu_{2}}{\nu_{1}}\right) \lim _{T \rightarrow \infty} E_{t} \sum_{i=0}^{T}\left(\frac{1}{\nu_{1}}\right)^{i} \widehat{\breve{c}}_{t+i}+\lim _{T \rightarrow \infty} E_{t}\left(\frac{1}{\nu_{1}}\right)^{T} \widehat{\breve{k}}_{t+T}
$$

Excluding explosive pathes, i.e. $\lim _{T \rightarrow \infty} E_{t}\left(1 / \nu_{1}\right)^{T} \widehat{\breve{k}}_{t+T}=0$, and using (12), one gets the decision rule on consumption:

$$
\widehat{\breve{c}}_{t}=\left(\frac{\nu_{1}-\varphi}{\nu_{2}}\right)\left(\widehat{\breve{k}}_{t}-\left(\sigma_{z} \varepsilon_{z, t}+\sigma_{b} \varepsilon_{b, t}\right)\right)
$$

After substituting (14) into (13), the dynamics of capital is given by:

$$
\widehat{\breve{k}}_{t+1}=\varphi\left(\widehat{\breve{k}}_{t}-\left(\sigma_{z} \varepsilon_{z, t}+\sigma_{b} \varepsilon_{b, t}\right)\right)
$$

The persistence properties of the model is thus governed by the parameter $\varphi \in(0,1)$. The decision rules of the other (deflated) variables are similar to equation (14). The consumption to 
output ratio is given by

$$
\begin{aligned}
\log \left(C_{t}\right)-\log \left(Y_{t}\right) & =\nu_{c y}\left(\widehat{k}_{t}-\left(\sigma_{z} \varepsilon_{z, t}+\sigma_{b} \varepsilon_{b, t}\right)\right) \\
& =\nu_{c y}\left(-\frac{\varphi}{1-\varphi L}\left(\sigma_{z} \varepsilon_{z, t-1}+\sigma_{b} \varepsilon_{b, t-1}\right)-\left(\sigma_{z} \varepsilon_{z, t}+\sigma_{b} \varepsilon_{b, t}\right)\right) \\
& =\nu_{c y}\left(-\frac{\left(\sigma_{z} \varepsilon_{z, t}+\sigma_{b} \varepsilon_{b, t}\right)}{1-\varphi L}\right)
\end{aligned}
$$

where $\nu_{c y}=\alpha\left(\nu_{1}-\varphi-\nu_{2}\right) / \nu_{2}$. The latter expression shows that the consumption to output ratio follows exactly the same stochastic process (an autoregressive process of order one) as the deflated capital $\log \left(K_{t} /\left(Z_{t-1} B_{t-1}\right)\right)$ in equation (15). The consumption to output ratio is thus an exact representation of the relevant state variable of the model. Notice than both shocks have a transitory effect on the ratio. Hours do not display a similar pattern. Using (9) and the above expression, the growth rate of hours is given by:

$$
(1-\varphi L) \Delta \log \left(H_{t}\right)=\nu_{c y} \sigma_{z} \Delta \varepsilon_{z, t}+\left(1+\nu_{c y}\right)\left(1-\left(\frac{\varphi+\nu_{c y}}{1+\nu_{c y}}\right) L\right) \sigma_{b} \varepsilon_{b, t}
$$

where $\Delta \log \left(H_{t}\right)=\Delta \widehat{\breve{h}}_{t}+\varepsilon_{b, t}$. The technology shock has no long-run effect on hours, whereas the preference shock increases hours permanently. More importantly, hours follow an $\operatorname{ARMA}(1,1)$ process, with an unit root in the moving average representation of the technology shock. It follows that finite autoregressions may be problematic in properly uncovering the true dynamics of hours. 
Table 1: Calibrated Values

\begin{tabular}{cccccc}
\hline \hline Deep Parameters & \multicolumn{3}{c}{$\begin{array}{c}\text { Shocks Parameters } \\
\text { (benchmark) }\end{array}$} & \multicolumn{3}{c}{$\begin{array}{c}\text { Shocks Parameters } \\
\text { (alternative) }\end{array}$} \\
\hline$\beta$ & 0.9926 & $\sigma_{z}$ & 0.01 & $\sigma_{\chi} / \sigma_{z}$ & {$[0.5 ; 1 ; 2]$} \\
$\alpha$ & 0.330 & $\rho_{\chi}$ & 0.95 & $\rho_{\chi}$ & {$[0.9 ; 0.95 ; 0.99]$} \\
$\delta$ & 0.0150 & $\sigma_{\chi}$ & 0.01 & & \\
$\gamma_{z}$ & 0.0036 & $\rho_{g}$ & 0.95 & & \\
$\psi$ & 2.500 & $\sigma_{g}$ & 0.01 & $\sigma_{g} /\left(\sigma_{z}, \sigma_{\chi}\right)$ & {$[1 ; 2]$} \\
$\bar{G} / \bar{Y}$ & {$[0 ; 0.20]$} & & & & \\
\hline \hline
\end{tabular}


Table 2: Simulation Results with two shocks: Cumulative Absolute Biais

\begin{tabular}{lclcccc}
\hline \hline & & \multicolumn{4}{c}{ Horizon } \\
$\rho_{\chi}$ & $\sigma_{\chi} / \sigma_{z}$ & Model & 0 & 0 to 4 & 0 to 8 & 0 to 12 \\
\hline 0.90 & 0.5 & DSVAR & 0.321 & 1.527 & 2.582 & 3.477 \\
& & LSVAR & 0.046 & 0.151 & 0.267 & 0.563 \\
& & CYSVAR-AR(1) & 0.036 & 0.186 & 0.352 & 0.550 \\
& \multirow{2}{*}{1} & DSVAR & 1.001 & 4.718 & 8.220 & 11.567 \\
& & LSVAR & 0.268 & 1.026 & 1.225 & 1.385 \\
& \multirow{2}{*}{2} & CYSVAR-AR(1) & 0.106 & 0.379 & 0.456 & 0.527 \\
& & DSVAR & 2.614 & 12.327 & 21.688 & 30.911 \\
& & LSVAR & 1.073 & 4.227 & 5.755 & 6.302 \\
& CYSVAR-AR(1) & 0.618 & 2.433 & 3.467 & 3.952 \\
\hline 0.95 & 0.5 & DSVAR & 0.294 & 1.453 & 2.492 & 3.372 \\
& & LSVAR & 0.045 & 0.172 & 0.211 & 0.339 \\
& \multirow{2}{*}{1} & CYSVAR-AR(1) & 0.045 & 0.217 & 0.387 & 0.569 \\
& & DSVAR & 0.917 & 4.493 & 7.923 & 11.202 \\
& & LSVAR & 0.290 & 1.250 & 1.827 & 2.101 \\
& \multirow{2}{*}{2} & CYSVAR-AR(1) & 0.097 & 0.412 & 0.613 & 0.709 \\
& & DSVAR & 2.405 & 11.789 & 20.988 & 30.051 \\
& & LSVAR & 1.170 & 5.120 & 7.851 & 9.632 \\
& CYSVAR-AR(1) & 0.622 & 2.742 & 4.332 & 5.471 \\
\hline 0.99 & 0.5 & DSVAR & 0.221 & 1.118 & 1.915 & 2.555 \\
& & LSVAR & 0.001 & 0.009 & 0.024 & 0.049 \\
& \multirow{2}{*}{1} & CYSVAR-AR(1) & 0.090 & 0.421 & 0.724 & 1.006 \\
& & DSVAR & 0.703 & 3.511 & 6.212 & 8.763 \\
& & LSVAR & 0.196 & 0.926 & 1.552 & 2.073 \\
& CYSVAR-AR(1) & 0.046 & 0.196 & 0.309 & 0.405 \\
& \multirow{2}{*}{2} & DSVAR & 1.943 & 9.687 & 17.332 & 24.842 \\
& & LSVAR & 0.926 & 4.397 & 7.404 & 9.948 \\
& CYSVAR-AR(1) & 0.241 & 1.185 & 2.067 & 2.856 \\
\hline \hline
\end{tabular}


Table 3: Simulation Results with two shocks: Cumulative Root Mean Square Errors

\begin{tabular}{|c|c|c|c|c|c|c|}
\hline \multirow[b]{2}{*}{$\rho_{\chi}$} & \multirow[b]{2}{*}{$\sigma_{\chi} / \sigma_{z}$} & \multirow[b]{2}{*}{ Model } & \multicolumn{4}{|c|}{ Horizon } \\
\hline & & & 0 & {$[0: 4]$} & {$[0: 8]$} & {$[0: 12]$} \\
\hline \multirow[t]{9}{*}{0.90} & 0.5 & DSVAR & 0.346 & 1.683 & 2.895 & 3.970 \\
\hline & & LSVAR & 0.224 & 0.989 & 1.605 & 2.163 \\
\hline & & CYSVAR $-A R(1)$ & 0.207 & 0.962 & 1.655 & 2.285 \\
\hline & 1 & DSVAR & 1.029 & 4.899 & 8.560 & 12.076 \\
\hline & & LSVAR & 0.500 & 2.119 & 3.167 & 3.915 \\
\hline & & CYSVAR $-A R(1)$ & 0.381 & 1.708 & 2.872 & 3.886 \\
\hline & 2 & DSVAR & 2.645 & 12.540 & 22.077 & 31.477 \\
\hline & & LSVAR & 1.327 & 5.460 & 7.877 & 9.301 \\
\hline & & CYSVAR $-A R(1)$ & 0.944 & 4.049 & 6.498 & 8.515 \\
\hline \multirow[t]{9}{*}{0.95} & 0.5 & DSVAR & 0.318 & 1.610 & 2.815 & 3.889 \\
\hline & & LSVAR & 0.239 & 1.123 & 1.865 & 2.492 \\
\hline & & CYSVAR $-A R(1)$ & 0.208 & 1.001 & 1.782 & 2.516 \\
\hline & 1 & DSVAR & 0.944 & 4.670 & 8.271 & 11.729 \\
\hline & & LSVAR & 0.545 & 2.495 & 3.993 & 5.123 \\
\hline & & CYSVAR $-A R(1)$ & 0.384 & 1.833 & 3.213 & 4.490 \\
\hline & 2 & DSVAR & 2.434 & 11.993 & 21.379 & 30.633 \\
\hline & & LSVAR & 1.434 & 6.459 & 10.193 & 12.907 \\
\hline & & CYSVAR $-A R(1)$ & 0.969 & 4.489 & 7.600 & 10.362 \\
\hline \multirow[t]{9}{*}{0.99} & 0.5 & DSVAR & 0.245 & 1.277 & 2.254 & 3.111 \\
\hline & & LSVAR & 0.265 & 1.299 & 2.254 & 3.110 \\
\hline & & CYSVAR $-A R(1)$ & 0.203 & 1.010 & 1.840 & 2.671 \\
\hline & 1 & DSVAR & 0.729 & 3.685 & 6.567 & 9.313 \\
\hline & & LSVAR & 0.551 & 2.680 & 4.621 & 6.349 \\
\hline & & CYSVAR $-A R(1)$ & 0.338 & 1.674 & 3.051 & 4.443 \\
\hline & 2 & DSVAR & 1.969 & 9.878 & 17.715 & 25.423 \\
\hline & & LSVAR & 1.3011 & 6.300 & 10.782 & 14.740 \\
\hline & & CYSVAR $-A R(1)$ & 0.706 & 3.841 & 6.305 & 9.137 \\
\hline
\end{tabular}


Table 4: Simulation Results with two shocks: Correlation

\begin{tabular}{|c|c|c|c|c|}
\hline$\rho_{\chi}$ & $\overline{\sigma_{\chi} / \sigma_{z}}$ & Model & $\overline{C o r r}\left(\varepsilon_{z}, \boldsymbol{\eta}^{T}\right)$ & $\overline{C \operatorname{Corr}\left(\varepsilon_{\chi}, \boldsymbol{\eta}^{T}\right)}$ \\
\hline \multirow[t]{9}{*}{0.90} & 0.5 & DSVAR & 0.908 & 0.325 \\
\hline & & LSVAR & 0.937 & -0.085 \\
\hline & & CYSVAR & 0.943 & 0.030 \\
\hline & 1 & DSVAR & 0.796 & 0.528 \\
\hline & & LSVAR & 0.923 & -0.181 \\
\hline & & CYSVAR & 0.942 & -0.053 \\
\hline & 2 & DSVAR & 0.625 & 0.707 \\
\hline & & LSVAR & 0.879 & -0.340 \\
\hline & & CYSVAR & 0.928 & -0.177 \\
\hline \multirow[t]{9}{*}{0.95} & 0.5 & DSVAR & 0.909 & 0.326 \\
\hline & & LSVAR & 0.921 & -0.097 \\
\hline & & CYSVAR & 0.937 & 0.044 \\
\hline & 1 & DSVAR & 0.799 & 0.531 \\
\hline & & LSVAR & 0.898 & -0.215 \\
\hline & & CYSVAR & 0.931 & -0.047 \\
\hline & 2 & DSVAR & 0.626 & 0.716 \\
\hline & & LSVAR & 0.834 & -0.404 \\
\hline & & CYSVAR & 0.912 & -0.189 \\
\hline \multirow[t]{9}{*}{0.99} & 0.5 & DSVAR & 0.921 & 0.297 \\
\hline & & LSVAR & 0.882 & -0.068 \\
\hline & & CYSVAR & 0.929 & 0.116 \\
\hline & 1 & DSVAR & 0.827 & 0.498 \\
\hline & & LSVAR & 0.853 & -0.197 \\
\hline & & CYSVAR & 0.917 & 0.065 \\
\hline & 2 & DSVAR & 0.650 & 0.708 \\
\hline & & LSVAR & 0.793 & -0.395 \\
\hline & & CYSVAR & 0.908 & -0.045 \\
\hline
\end{tabular}


Table 5: Simulation Results with Three Shocks

\begin{tabular}{|c|c|c|c|c|c|c|}
\hline \multicolumn{7}{|c|}{ Average Cumulative Absolute Biais } \\
\hline \multirow[b]{2}{*}{ Variables } & \multirow[b]{2}{*}{$\sigma_{g} /\left(\sigma_{z}, \sigma_{\chi}\right)$} & \multirow[b]{2}{*}{ Model } & \multicolumn{4}{|c|}{ Horizon } \\
\hline & & & 0 & 0 to 4 & 0 to 8 & 0 to 12 \\
\hline \multirow{6}{*}{$(y-h, h)$} & \multirow[t]{3}{*}{1} & DSVAR & 1.037 & 5.081 & 8.930 & 12.568 \\
\hline & & LSVAR & 0.286 & 1.208 & 1.692 & 1.832 \\
\hline & & CYSVAR $-A R(1)$ & 0.046 & 0.224 & 0.413 & 0.623 \\
\hline & \multirow[t]{3}{*}{2} & DSVAR & 1.071 & 5.243 & 9.216 & 12.980 \\
\hline & & LSVAR & 0.278 & 1.175 & 1.652 & 1.794 \\
\hline & & CYSVAR $-A R(1)$ & 0.072 & 0.343 & 0.605 & 0.873 \\
\hline \multirow[t]{6}{*}{$(y-h, h, c-y)$} & \multirow[t]{3}{*}{1} & DSVAR & 0.112 & 0.555 & 1.200 & 2.091 \\
\hline & & LSVAR & 0.197 & 0.805 & 1.251 & 1.585 \\
\hline & & CYSVAR $-A R(1)$ & 0.046 & 0.224 & 0.413 & 0.623 \\
\hline & \multirow[t]{3}{*}{2} & DSVAR & 0.151 & 0.741 & 1.501 & 2.468 \\
\hline & & LSVAR & 0.198 & 0.808 & 1.248 & 1.560 \\
\hline & & CYSVAR $-A R(1)$ & 0.072 & 0.343 & 0.605 & 0.873 \\
\hline \multicolumn{7}{|c|}{ Cumulative Root Mean Square Errors } \\
\hline \multirow{8}{*}{$\begin{array}{l}\text { Vairables } \\
(y-h, h)\end{array}$} & & & \multicolumn{4}{|c|}{ Horizon } \\
\hline & $\sigma_{g} /\left(\sigma_{z}, \sigma_{\chi}\right)$ & Model & 0 & 0 to 4 & 0 to 8 & 0 to 12 \\
\hline & 1 & DSVAR & 1.064 & 5.254 & 9.269 & 13.084 \\
\hline & & LSVAR & 0.531 & 2.416 & 3.8547 & 4.9571 \\
\hline & & CYSVAR-AR(1) & 0.392 & 1.887 & 3.343 & 4.688 \\
\hline & 2 & DSVAR & 1.097 & 5.416 & 9.557 & 13.499 \\
\hline & & LSVAR & 0.544 & 2.472 & 3.949 & 5.083 \\
\hline & & CYSVAR $-A R(1)$ & 0.402 & 1.936 & 3.436 & 4.829 \\
\hline \multirow[t]{6}{*}{$(y-h, h, c-y)$} & 1 & DSVAR & 0.502 & 2.435 & 4.261 & 6.042 \\
\hline & & LSVAR & 0.603 & 2.673 & 4.190 & 5.340 \\
\hline & & CYSVAR-AR(1) & 0.392 & 1.887 & 3.343 & 4.688 \\
\hline & 2 & DSVAR & 0.534 & 2.575 & 4.487 & 6.332 \\
\hline & & LSVAR & 0.574 & 2.570 & 4.064 & 5.209 \\
\hline & & CYSVAR-AR(1) & 0.402 & 1.936 & 3.436 & 4.829 \\
\hline
\end{tabular}


Table 6: Simulation Results with three shocks: Correlation

\begin{tabular}{lclc}
\hline \hline Variables & $\sigma_{g} /\left(\sigma_{z}, \sigma_{\chi}\right)$ & Model & $\operatorname{Corr}\left(\varepsilon_{z}, \boldsymbol{\eta}^{T}\right)$ \\
\hline$(y-h, h)$ & 1 & DSVAR & 0.774 \\
& & LSVAR & 0.904 \\
& & CYSVAR & 0.928 \\
& \multirow{2}{*}{2} & DSVAR & 0.767 \\
& & LSVAR & 0.904 \\
& & CYSVAR & 0.914 \\
\hline$(y-h, h, c-y)$ & \multirow{2}{*}{1} & DSVAR & 0.908 \\
& & LSVAR & 0.827 \\
& & CYSVAR & 0.928 \\
& \multirow{2}{*}{2} & DSVAR & 0.898 \\
& & LSVAR & 0.817 \\
& & CYSVAR & 0.914 \\
\hline \hline
\end{tabular}


Figure 1: Data Used in SVARs

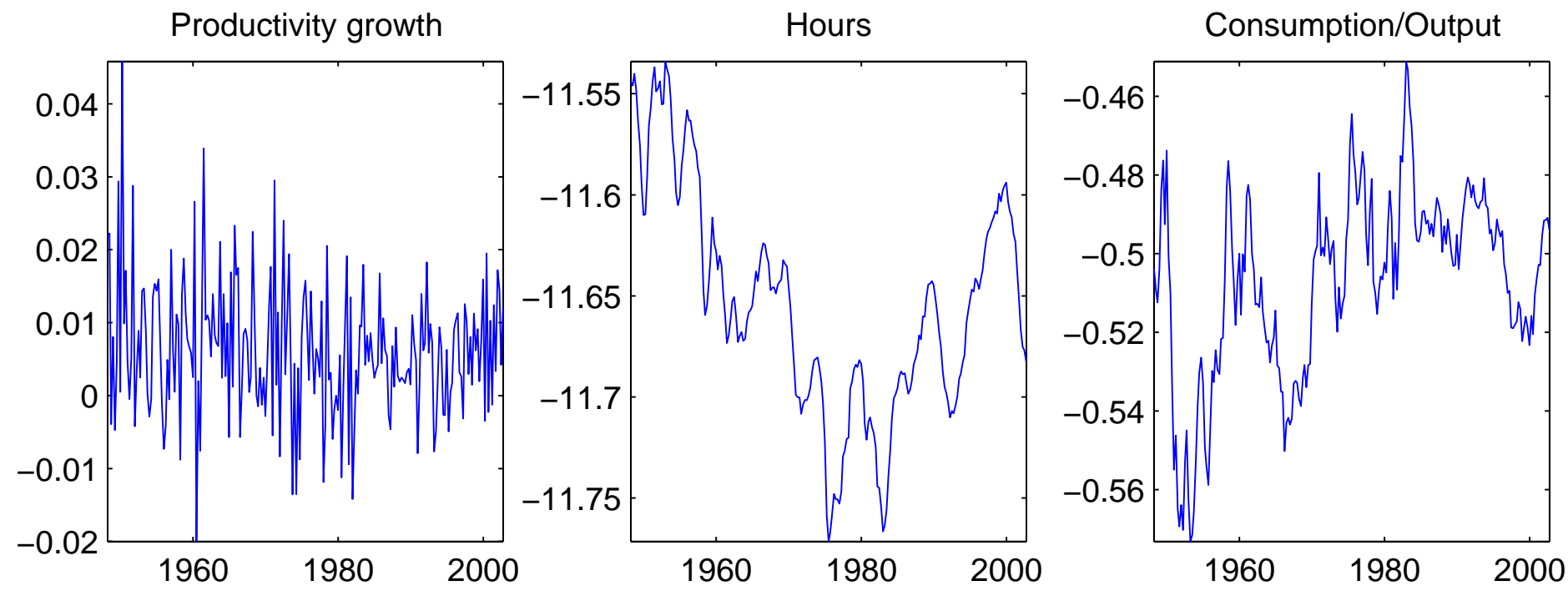


Figure 2: Response of Hours (in logs) to a Positive Technology Shock (two-variables)

(a) Level Specification

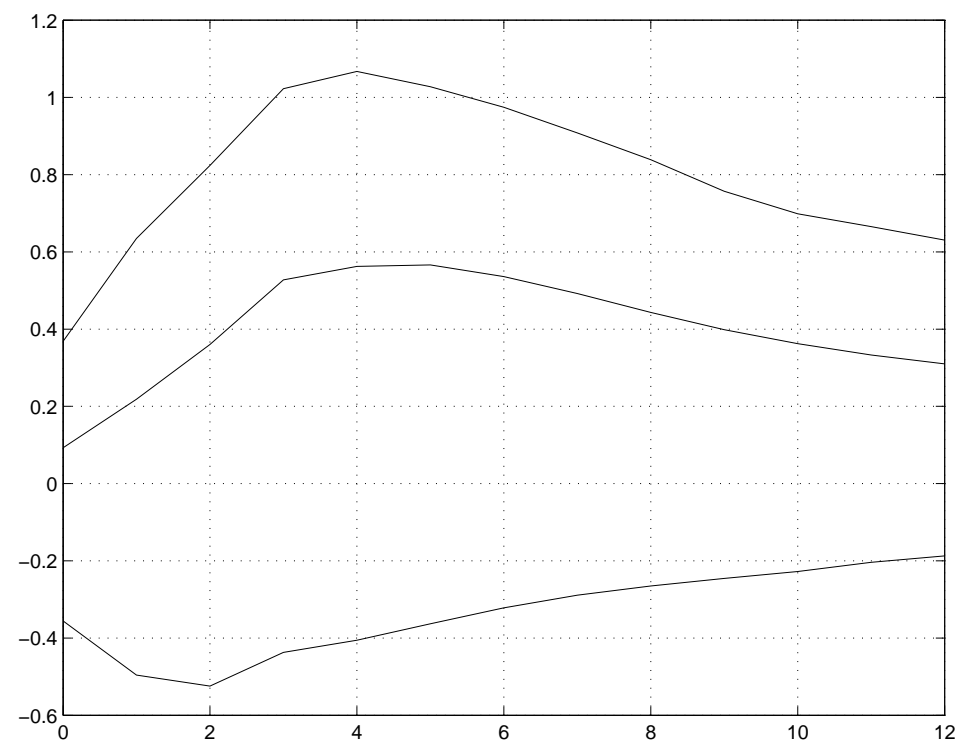

(b) Difference Specification

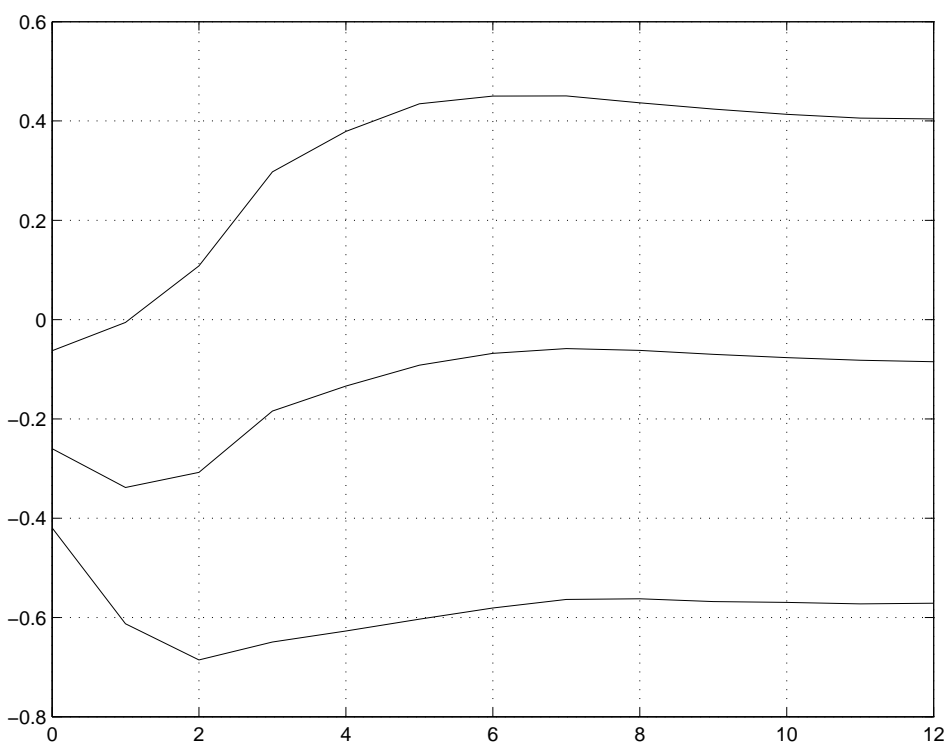


Figure 3: Response of Hours (in logs) to a Positive Technology Shock (three-variables)

(a) Level Specification

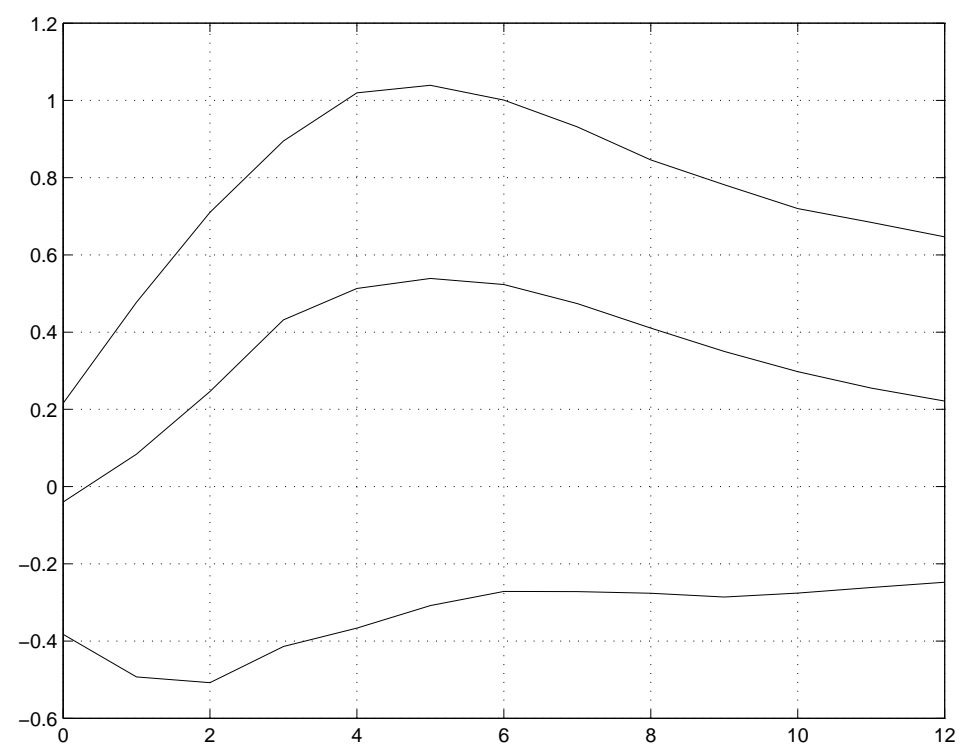

(b) Difference Specification

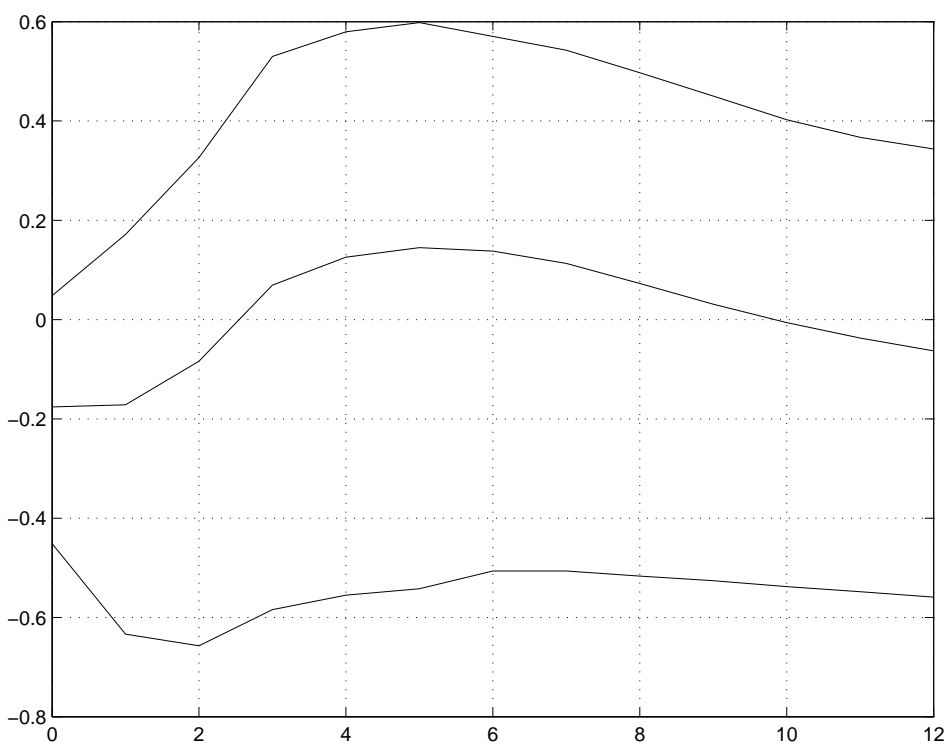


Figure 4: True and Estimated IRFs of hours with DSVAR and LSVAR (two shocks and benchmark calibration)

\section{(a) DSVAR}

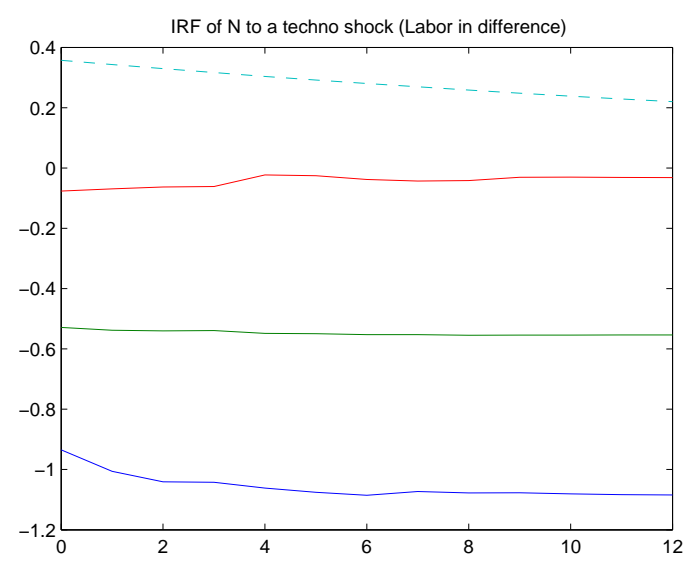

(b) LSVAR

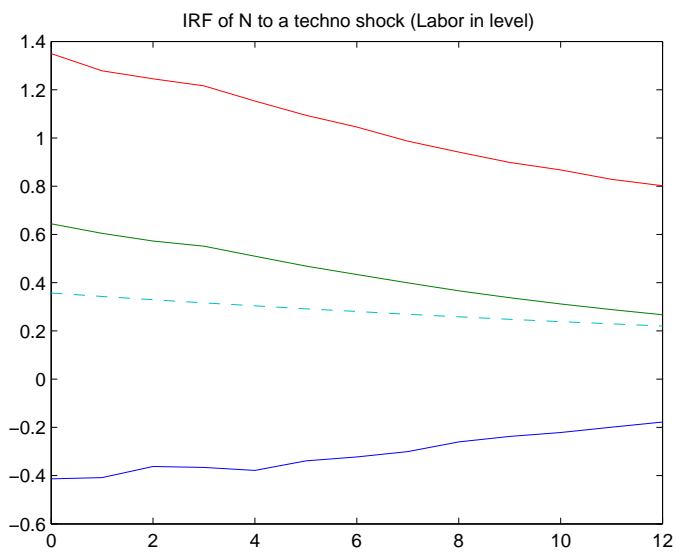


Figure 5: True and Estimated IRFs of hours with CYSVARs (two shocks and benchmark calibration)

(a) CYSVAR- $h$

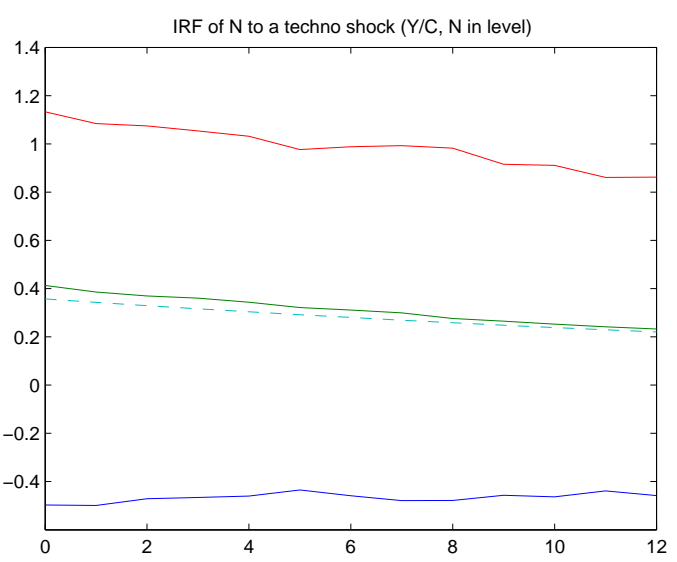

(b) CYSVAR- $\Delta h$

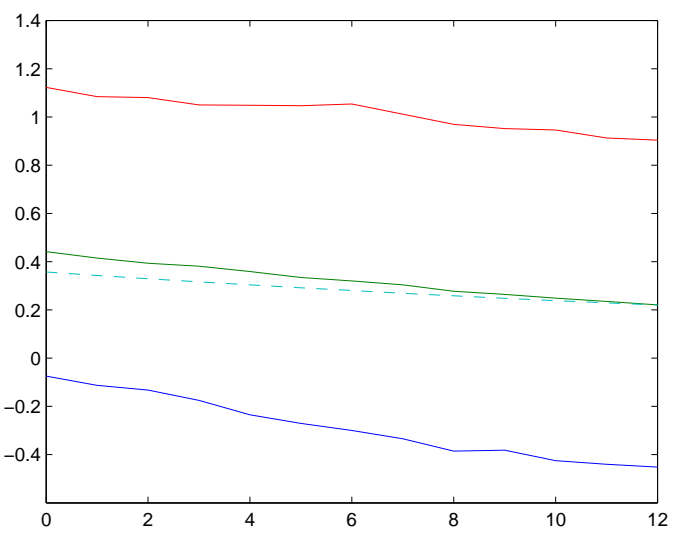

(c) CYSVAR- $A R(1)$

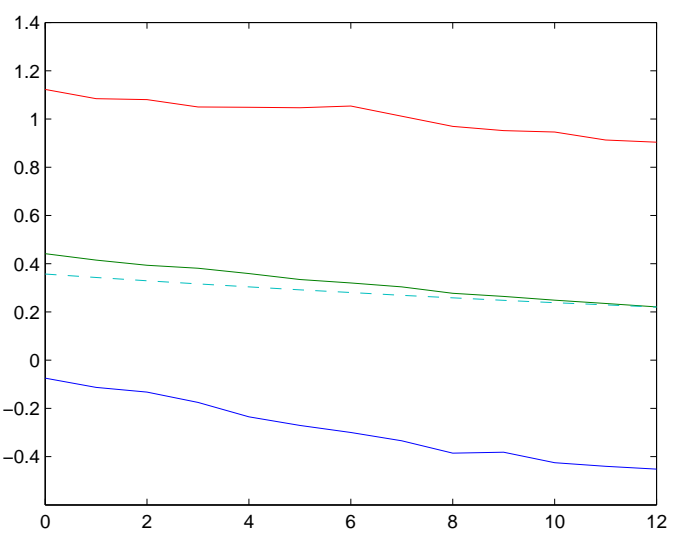


Figure 6: Autocorrelation function (preference shock)

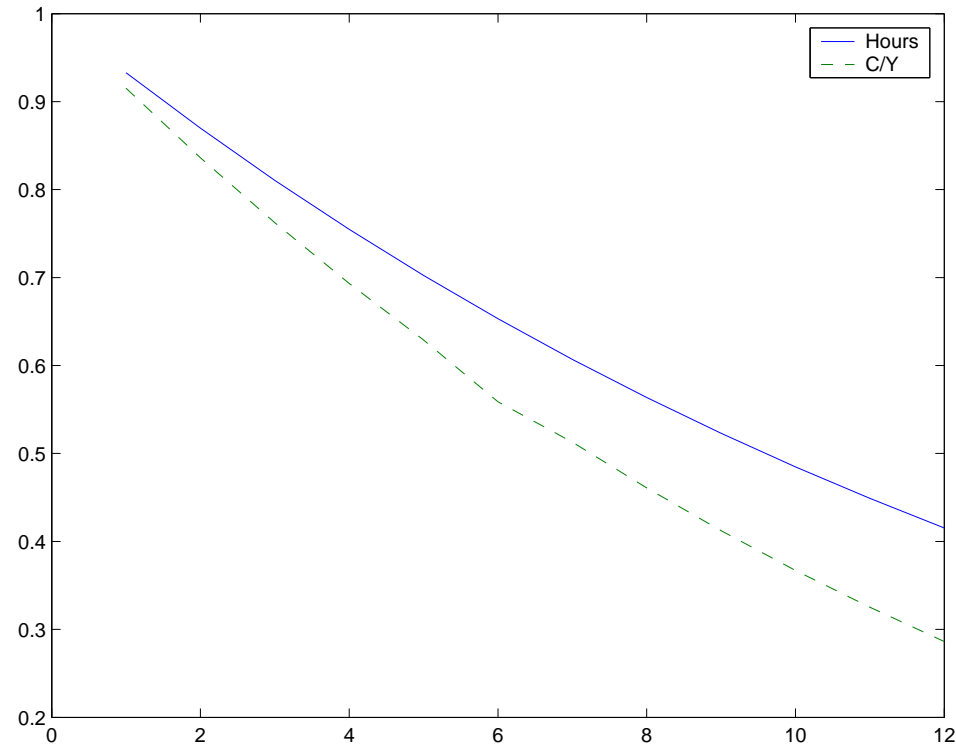

Figure 7: Autocorrelation function (technology and preference shock)

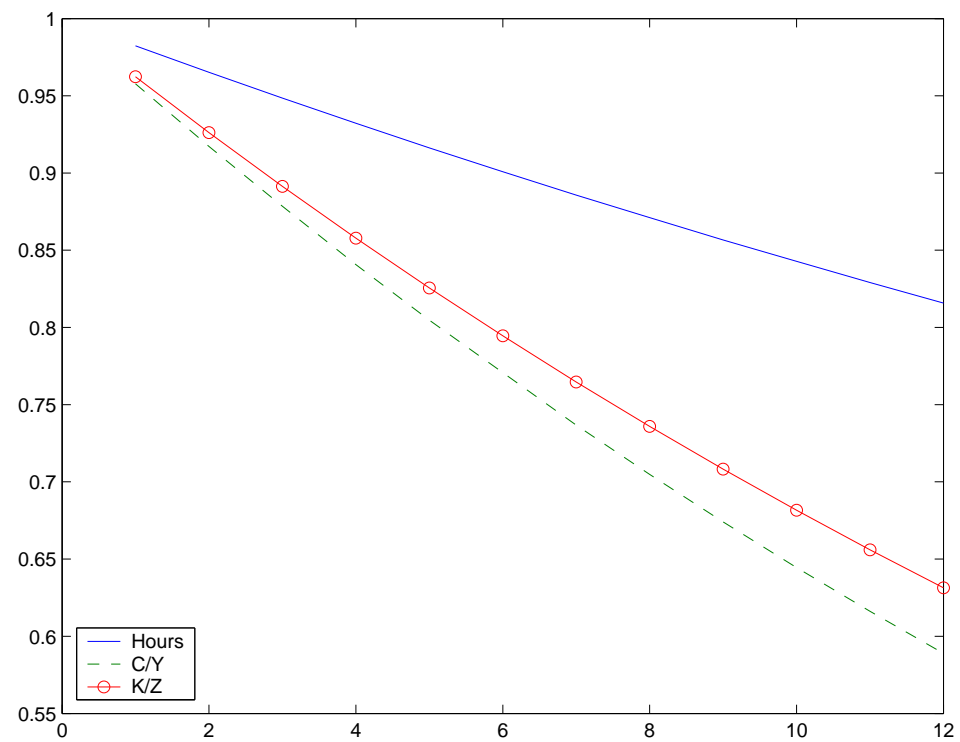


Figure 8: True and Estimated IRFs of hours with DSVAR, LSVAR and CYSVAR-AR(1) (three shocks, two variables and benchmark calibration)

\section{(a) DSVAR}

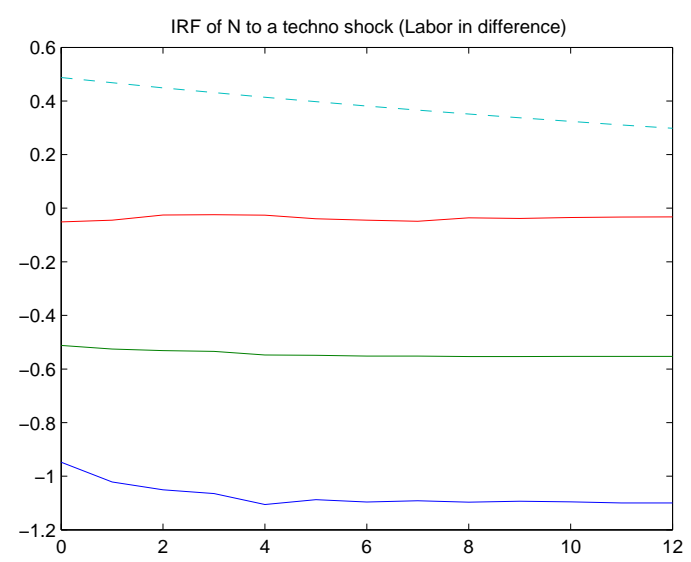

(b) LSVAR

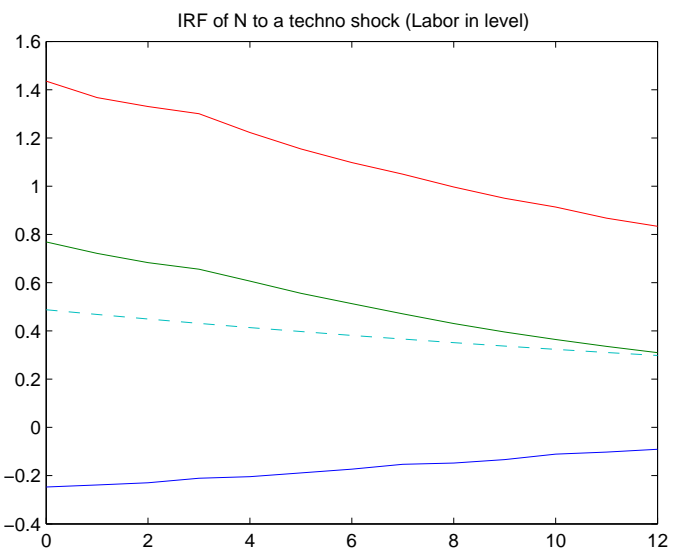

(b) CYSVAR-AR(1)

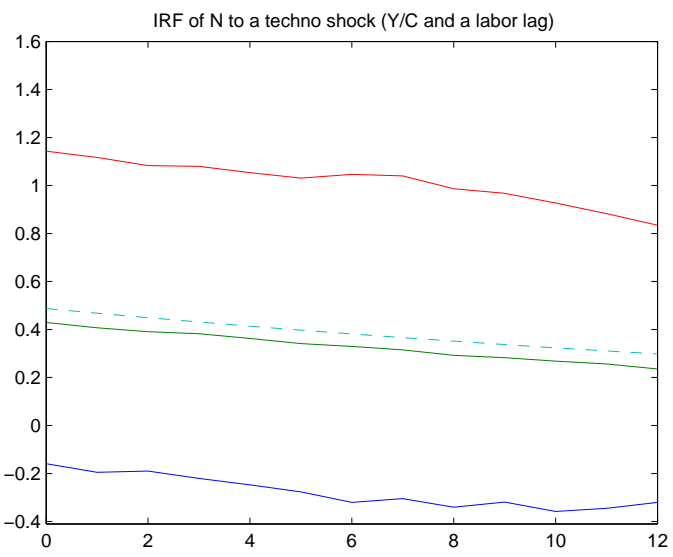


Figure 9: True and Estimated IRFs of hours with DSVAR, LSVAR and CYSVAR-AR(1) (three shocks, three variables and benchmark calibration)

\section{(a) DSVAR}

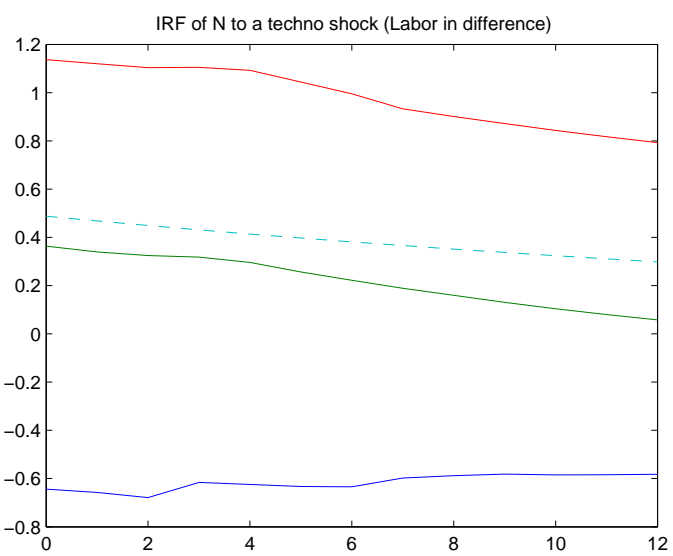

(b) LSVAR

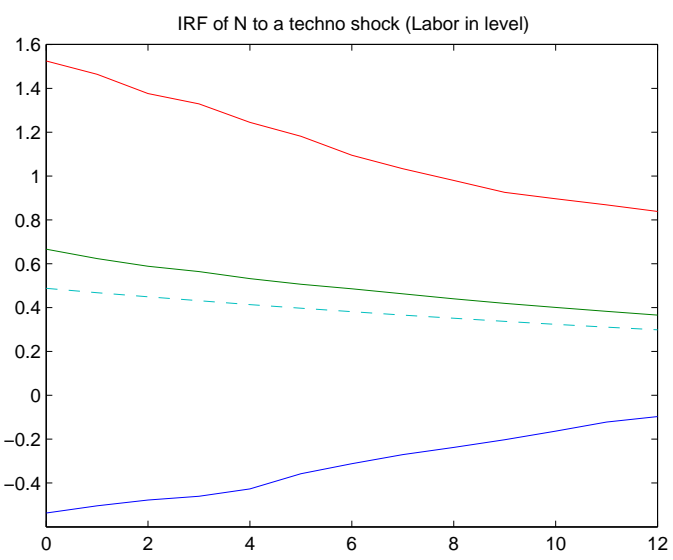

(b) CYSVAR-AR(1)

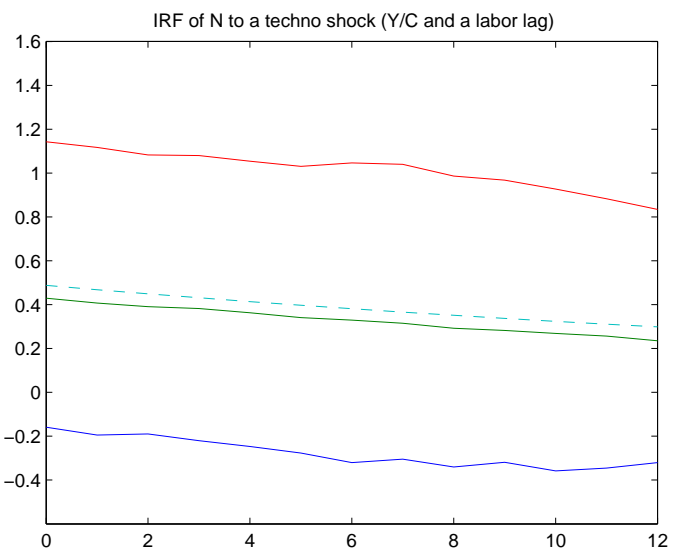


Figure 10: IRFs of hours in CYSVAR-AR(1)

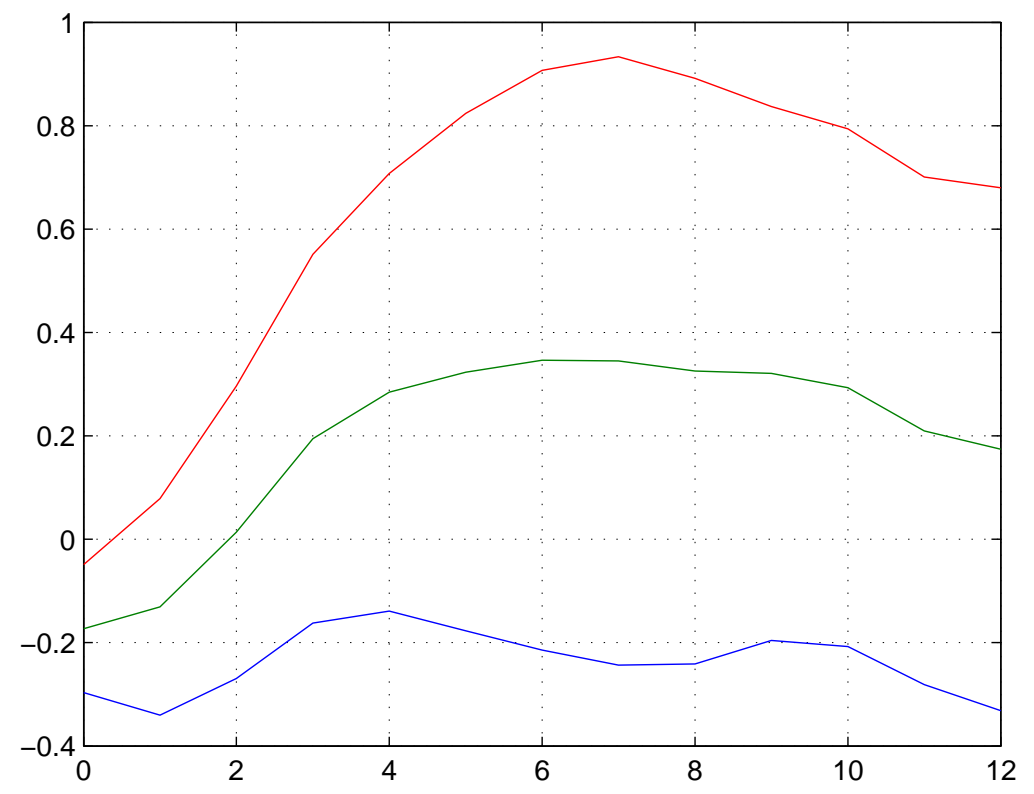


Figure 11: IRFs of hours in LSVAR with breaks in labor productivity (a) LSVAR

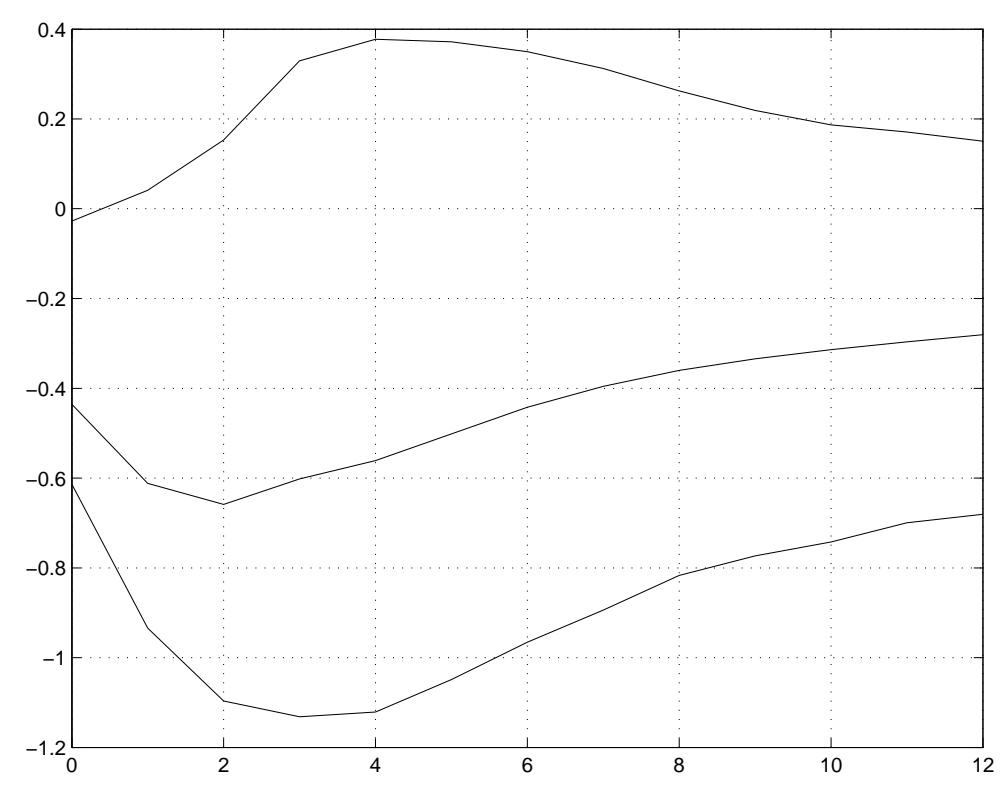

(b) CYSVAR-AR(1)

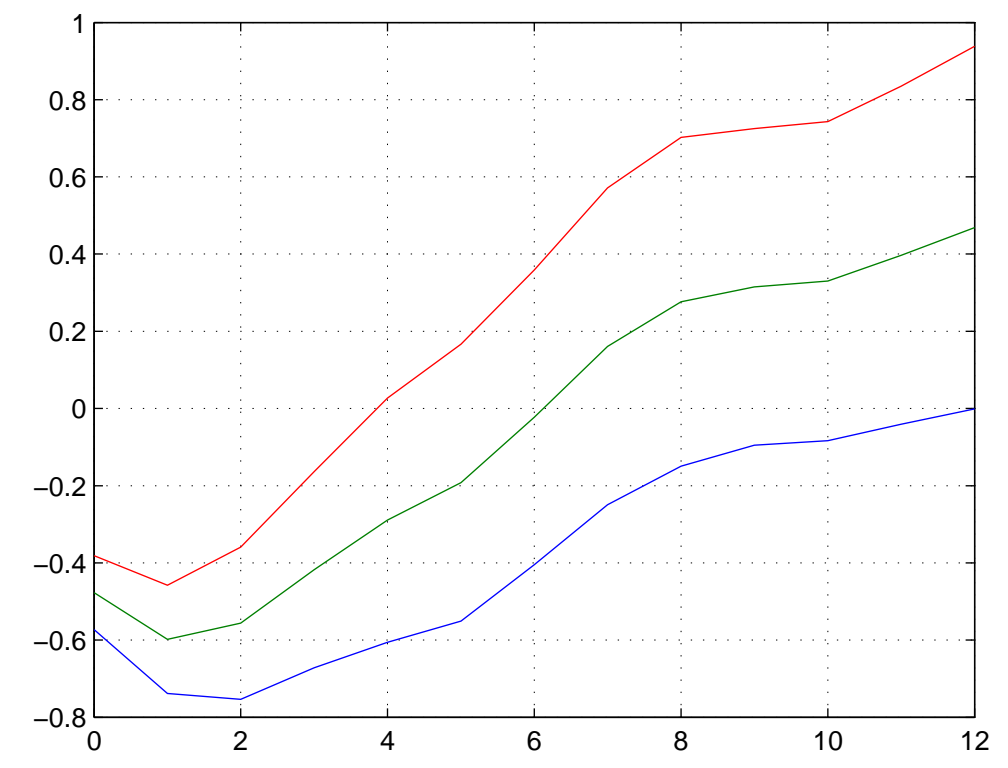

